\title{
Using principal component analysis and annual seasonal trend analysis to assess karst rocky desertification in southwestern China
}

\author{
Zhiming Zhang $($ D $\cdot$ Zhiyun Ouyang $・$ Yi Xiao • \\ Yang Xiao • Weihua Xu
}

Received: 15 December 2016 / Accepted: 24 April 2017 / Published online: 16 May 2017

(C) Springer International Publishing Switzerland 2017

\begin{abstract}
Increasing exploitation of karst resources is causing severe environmental degradation because of the fragility and vulnerability of karst areas. By integrating principal component analysis (PCA) with annual seasonal trend analysis (ASTA), this study assessed karst rocky desertification (KRD) within a spatial context. We first produced fractional vegetation cover (FVC) data from a moderate-resolution imaging spectroradiometer normalized difference vegetation index using a dimidiate pixel model. Then, we generated three main components of the annual FVC data using PCA. Subsequently, we generated the slope image of the annual seasonal trends of FVC using median trend analysis. Finally, we combined the three PCA components and annual seasonal trends of FVC with the
\end{abstract}

Z. Zhang $\cdot$ Z. Ouyang $\cdot$ Y. Xiao $\cdot$ Y. Xiao $\cdot$ W. Xu $(\bowtie)$

State Key Laboratory of Urban and Regional Ecology, Research Center for Eco-Environmental Sciences, Chinese Academy of

Sciences, Beijing 100085, China

e-mail: xuweihua@rcees.ac.cn

Z. Zhang

e-mail: zhiming_zhang76@hotmail.com

Z. Ouyang

e-mail: zyouyang@ rcees.ac.cn

Y. Xiao

e-mail: xiaoyi@rcees.ac.cn

Y. Xiao

e-mail: xyrcees@163.com

Z. Zhang

School of Ecology and Environmental Science, Yunnan

University, Kunming 650091, China incidence of KRD for each type of carbonate rock to classify KRD into one of four categories based on K-means cluster analysis: high, moderate, low, and none. The results of accuracy assessments indicated that this combination approach produced greater accuracy and more reasonable KRD mapping than the average FVC based on the vegetation coverage standard. The KRD map for 2010 indicated that the total area of KRD was $78.76 \times 10^{3} \mathrm{~km}^{2}$, which constitutes about $4.06 \%$ of the eight southwest provinces of China. The largest KRD areas were found in Yunnan province. The combined PCA and ASTA approach was demonstrated to be an easily implemented, robust, and flexible method for the mapping and assessment of $\mathrm{KRD}$, which can be used to enhance regional KRD management schemes or to address assessment of other environmental issues.

Keywords MODIS - Normalized difference vegetation index $\cdot$ Fractional vegetation cover $\cdot$ Median trend analysis $\cdot$ Karst rocky desertification

\section{Introduction}

Karst is characterized by the predominance of rock dissolution over mechanical erosion. It is typical of present-day temperate (cold and warm) and tropical environments (Wang et al. 2004a; Ford and Williams 2007; De Waele et al. 2011), and it frequently occurs in some of the most fragile and vulnerable environments on earth (Brinkmann and Parise 2012). Currently, about 
$25 \%$ of Earth's population lives on or near karst areas (Ford and Williams 2007), and the increasing exploitation of karst resources (e.g., water and building materials) is causing severe environmental degradation and unsustainable resource use (Drew and Hötzl 1999; Gunn 2004; Bou Kheir et al. 2008; Parise et al. 2009; De Waele et al. 2011; Peng et al. 2013). In addition, the desertification of karst landscapes (i.e., karst rocky desertification, KRD), which is defined as a process of soil erosion, bedrock exposure, and reduction of land productivity, will most likely continue to increase (Drew 1983; Gillieson et al. 1996; Li et al. 2009; De Waele et al. 2011).

Southwestern China contains up to $530,000 \mathrm{~km}^{2}$ of karst landscapes, primarily located in Yunnan, Guizhou, and Guangxi provinces (Wang 2003; Wang et al. 2004a,b; Xiong et al. 2009; Peng et al. 2013). This region represents one of the world's most spectacular examples of humid tropical to subtropical karst landscapes. It also presents some of the most severe ecological and environmental issues in China (Wang et al. 2003). Accurate mapping and assessment of KRD is crucial for understanding the dynamics of karst landscapes and can provide insights for sustainable planning and management practices aimed at preserving essential ecosystem functions (Brinkmann and Parise 2012).

Remote sensing has been used widely to map, monitor, and assess KRD because of its relatively low cost of data acquisition and its availability for consistent repeated spatiotemporal measurements of the same or different large geographic areas (Huang and Cai 2009; Xia et al. 2006; Yue et al. 2010). Typically, four approaches have been used for KRD mapping, monitoring, and assessment: (1) image classification (i.e., visual interpretation, supervised and unsupervised image classification) (Xiong et al. 2002; Li and $\mathrm{Yu}$ 2002; Tong 2003; Hu et al. 2004; Huang and Cai 2009); (2) vegetation index (VI)-based approaches, such as the normalized difference vegetation index (NDVI) (Jiang et al. 2006; Ling et al. 2009; Li et al. 2010; Liu et al. 2010); (3) spectral mixture analysis (Chen et al. 2003; Xia et al. 2006; Yue et al. 2010); and (4) geographic information systems (GIS)-based approaches (Huang and Cai 2006; Yuksel et al. 2008; Yang et al. 2013). However, using traditional image classification to accurately map and assess KRD is difficult because land cover types in karst regions are often mixed, e.g., woody shrubs are often mixed with grass, trees, and rocks (Xia et al. 2006; Yue et al. 2010).

Yue et al. (2011) also mentioned that none of the existing vegetation indices could be used directly as an indicator to assess the degree of KRD because of the effects of mixed land cover and topography (i.e., shadow effects) in karst areas. Spectral mixture analysis (SMA) has been used to estimate the vegetation cover and non-vegetated areas (i.e., bare soil and exposed bedrock) in karst regions (Xia et al. 2006). The SMA method assumes mixed pixels in which each pixel is characterized by a finite number of dominant features (i.e., endmembers) that have relatively constant spectral properties (Adams et al. 1995; Yang et al. 2012). However, the SMA approach is often limited by the variability of endmembers, particularly for highly heterogeneous landscapes in karst regions (Price 1994; Yue et al. 2010). Recently, a KRD synthesis index (KRDSI) based on unique spectral features observed in non-vegetation land cover types (non-photosynthetic vegetation, bare soil, and exposed bedrock) has been developed for KRD assessment (Liu et al. 2010; Yue et al. 2010). This approach requires the collection of unique spectral features for numerous vegetation and non-vegetation land cover types. However, because of the effects of mixed land cover and topography in karst regions, it is difficult to upscale this approach from local case studies to a regional scale (such as the entire southwest of China), where the collection of corresponding spectral feature data might be more limited.

Landsat TM, ETM+, and SPOT 5 images constitute the data used most commonly for KRD mapping, monitoring, and assessment (Huang and Cai 2009; Xia et al. 2006; Tong et al. 2013; Zhang et al. 2014). However, it is almost impossible to find Landsat TM, ETM+, and SPOT 5 imagery data of sufficient quality that encompass the entire karst region within the eight provinces in southwest China for the same season within 1 year. KRD landscapes with sparse vegetation dominated by shrubs and herbaceous plants change dramatically with the season (Hou et al. 2015). Therefore, imagery data acquired in different seasons and different years for use in KRD mapping, monitoring, and assessment could contain many inherent errors and uncertainties. As a result, KRD mapping, monitoring, and assessment over the entire karst region in southwest China remain an important challenge in the fields of remote sensing and land change science (Tong et al. 2013). 
The moderate-resolution imaging spectroradiometer (MODIS) is an advanced sensor that can provide imagery and NDVI data with high temporal resolution (every 1.2 days) and wide spatial coverage $(705 \times 705 \mathrm{~km})$. MODIS image time series provide a critically important resource for understanding both the dynamics and the evolution of environmental phenomena (Eastman et al. 2013). MODIS data have been widely used in analyses of land cover change over large areas (Zhan et al. 2002; Galford et al. 2008), vegetation dynamic change and its driving forces in arid and semiarid regions (CampoBescós et al. 2013; Li et al. 2013; Bao et al. 2014; Liu and Lei 2015; Qu et al. 2015), and crop mapping and productivity estimation (Wardlow and Egbert, 2008; Mishra and Chaudhuri, 2015). Furthermore, MODIS NDVI time series data have been used to describe regional-scale temporal trends in vegetation by quantifying interannual and seasonal vegetation dynamics (Wardlow and Egbert, 2008; Mishra and Chaudhuri, 2015). Studies have demonstrated that NDVI trends are influenced by climatic fluctuation and/or land cover properties (Li et al. 2013; Parmentier 2014).

Recently, some researchers have addressed the relationships between NDVI trends and climate and topography variables in karst regions (Hou et al. 2015; Tong et al. 2016). Analyses of seasonal vegetation trends can provide important understanding of vegetation responses to both environmental and anthropogenic drivers of change (Peng et al. 2012a, b; Tong et al. 2016). The annual seasonal trends of vegetation could provide critical information regarding vegetation cover, productivity, and health status on large spatial and temporal scales (Peng et al. 2012b; Li et al. 2013; Hou et al. 2015; Peng et al. 2015). Therefore, the combination of seasonal vegetation trends with remote sensing and ancillary data (e.g., topographical and geological variables) might be helpful for KRD mapping and assessment in large karst regions.

The objective of this study was to develop a conceptual framework for the assessment of the current status and future prospects of KRD. With this framework, an attempt was made to provide an approach that helps link KRD assessment to regional planning. Thus, this study aimed to present a methodology that could integrate annual seasonal vegetation trends with remote sensing and ancillary data within a spatial context to support KRD mapping and assessment.

\section{Materials and methods}

Study area

The karst landscapes located in Yunnan, Guizhou, Sichuan, Hunan, Guangdong, Chongqing, and Hubei provinces and the Guangxi Autonomous region in southwestern China $\left(22^{\circ} 43^{\prime}-23^{\circ} 56^{\prime} \mathrm{N}, 103^{\circ} 37^{\prime}-\right.$ $105^{\circ} 23^{\prime}$ E) (Fig. 1) encompass up to $530,000 \mathrm{~km}^{2}$ (Wang et al. 2003; Wang and Li 2007). They represent one of the world's most spectacular examples of humid tropical to subtropical limestone karst landscapes. This region has the richest biological and ethnic diversity in China, housing more than 50 large-population ethnicities (Wang et al. 2004a). The heterogeneity of the karst landscapes in southwestern China is very high. Furthermore, the topographic variations within the karst region are also high; the elevations are generally high in the west and north, low in the east and south, and highest in the central areas. Moreover, the landforms in karst landscapes are diverse; dolines, poljes, uvalas, and karrens can all be found within this region (Tong et al. 2013).

Karst landscapes in southwestern China are characterized by the predominance of carbonate rock dissolution over mechanical erosion, which is typical of present-day temperate (cold and warm) and tropical climates (Ford and Williams 2007; Lei et al. 2009; Tong et al. 2013). The karst region is located on the slopes of the eastern flank of the Qinghai-Tibet Plateau, and it lies within the climatic zone between the Pacific and the Indian monsoons. This creates favorable conditions for the interaction of cold and warm air masses. The yearly average temperature is about $12-14^{\circ} \mathrm{C}$ in the west of the karst region, approximately $19{ }^{\circ} \mathrm{C}$ in the south, and about $14-18^{\circ} \mathrm{C}$ elsewhere. The rainfall in the region is abundant. The average annual precipitation is $800-1000 \mathrm{~mm}$ in the west, $>1800 \mathrm{~mm}$ in the south, and approximately $1000-1800 \mathrm{~mm}$ in other parts of the karst region (Wang et al. 2004a). This warm and moist monsoonal climate provides conditions conducive to erosion.

Data sources

\section{MODIS NDVI and DEM data}

MODIS NDVI data with 250-m spatial resolution obtained in 2010 (MODIS13A2) were used to classify the different levels of KRD. These data were downloaded 


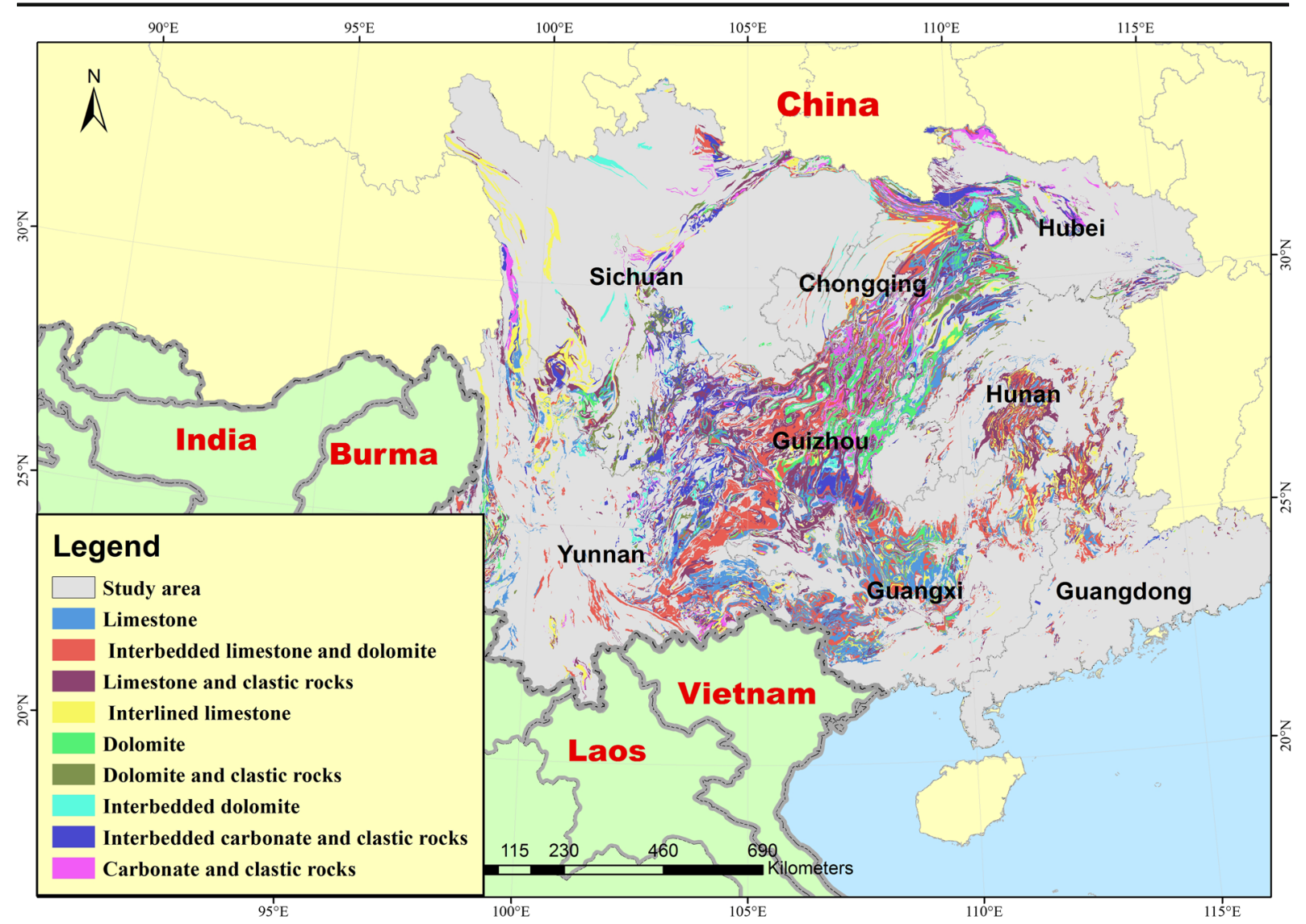

Fig. 1 Location of the study area and carbonate rock in southwestern China

from the Land Processes Distributed Active Archive Center (https://lpdaac.usgs.gov/dataset discovery/modis/modis_products_table/mod13q1). The tiles of these NDVI data were mosaicked and reprojected to the Albers Equal Area Projection using the World Geodetic System 1984 (WGS84) as a reference datum.

In addition, 90-m-resolution Shuttle Radar Topographic Mission digital elevation model (DEM) data, available from the Consultative Group on International Agricultural Research centers of the Consortium for Spatial Information (http://srtm.csi.cgiar. org/SELECTION/inputCoord.asp), were used in this study. Topographic slopes were produced using the DEM data, and based on fieldwork in the karst region, areas with slopes of $<5^{\circ}$ were determined as agricultural and urban areas. Moreover, the alpine region with elevations $>3900 \mathrm{~m}$, which is located mainly in the northwest of Yunnan and west of Sichuan provinces, was delineated using the DEM data. In this region, the rocky landscape and sparse vegetation are caused mainly by natural physical process, not human activities. Therefore, two constraints (slope $<5^{\circ}$ and elevation $>3900 \mathrm{~m}$ ) were generated based on the DEM data. All the data were projected to the Albers Equal Area Projection with the World Geodetic System 1984 (WGS84) as a reference datum.

\section{Map of carbonate rock}

As mentioned earlier, KRD in southwestern China is characterized by the predominance of carbonate rock dissolution over mechanical erosion. In this study, a map of the types of carbonate karst rock was obtained from the Chinese Academy of Geological Sciences (http://en.cags.ac.cn/) (Fig. 2). These carbonate rock type comprise limestone, interbedded limestone and dolomite, limestone and clastic rocks, interlined limestone, dolomite, interbedded dolomite, dolomite and clastic rocks, interbedded carbonate and clastic rocks, and clastic and carbonate rocks (Fig. 2). The dissolution processes of the different types of 
Fig. 2 Flowchart of the stepwise process used for KRD classification of southwestern China

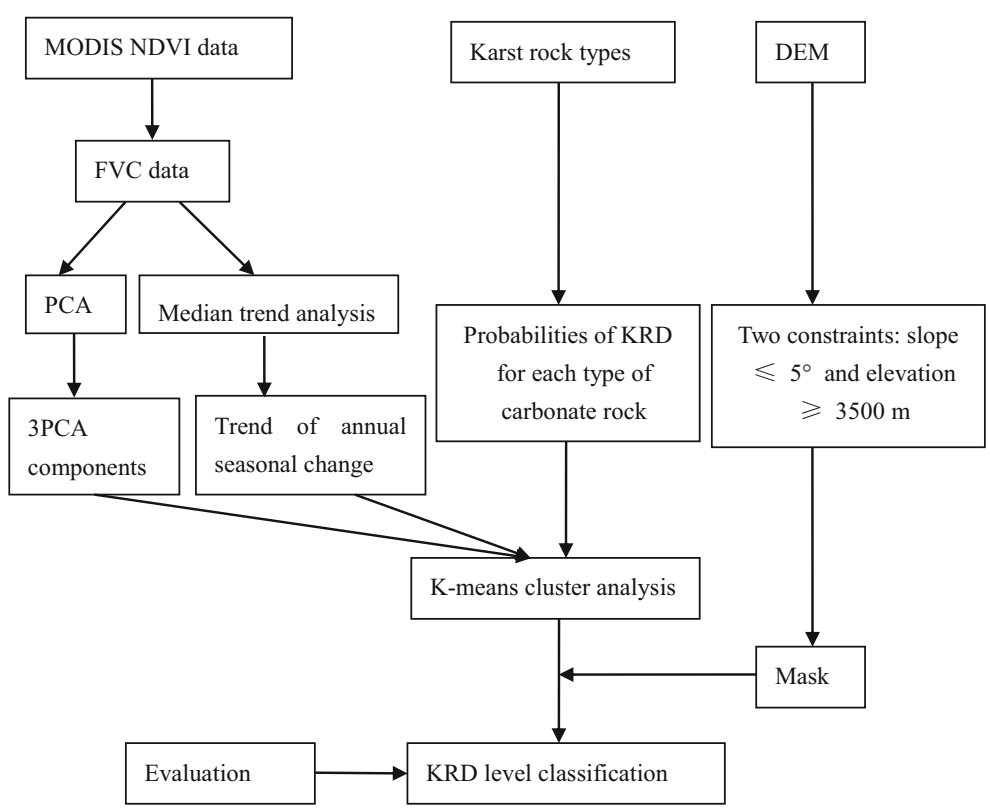

carbonate rock vary. Previous studies have illustrated that limestone, interbedded limestone and dolomite, and interbedded carbonate and clastic rocks have higher incidence of KRD: 29.86, 29.01, and 29.47\%, respectively. The incidence of KRD for clastic and carbonate rocks is about $15.83 \%$. Generally, carbonate rock with higher content of calcite is more prone to KRD. Conversely, carbonate rock with higher content of dolomite is less prone to KRD (Xiao et al. 2005; Lei et al. 2009). According to the incidence of KRD for each rock type, the different rock types were weighted and combined with MODIS NDVI data for KRD classification (Fig. 3).

A field survey (August-September 2012) was undertaken to establish the main characteristics and variability of KRD (Fig. 2), and to acquire reliable field data for evaluating the accuracy of the KRD assessment results. Moreover, topographic maps produced in the 1970s by the Chinese military at a scale of 1:100,000 were used to provide additional information regarding villages, towns, rivers, roads, and land cover.

\section{Methods}

Annual seasonal dynamics of vegetation cover are evident in karst regions (Fig. 2). Therefore, the annual seasonal trends of vegetation were combined with principal components analysis (PCA) components and other ancillary data for KRD assessment, in which a stepwise process was used to identify the degrees of KRD (Fig. 4). The process included five steps: (1) fractional vegetation cover (FVC) data were generated using NDVI data; (2) three main components of the annual FVC data in 2010 were obtained using PCA; (3) the slope image of annual seasonal trends of FVC was generated using median trend (Theil-Sen, TS) analysis; (4) the combination of the three PCA components and seasonal trends of FVC with the incidence of KRD for each type of carbonate rock was used to classify the level of KRD using K-means cluster analysis; and (5) the results of the integration of PCA and an annual seasonal trends analysis (ASTA) approach were compared with those obtained using the multicriteria evaluation (MCE) method in our previous study (Zhang et al. 2014).

\section{Fractional vegetation cover}

Previous studies have shown that vegetation cover is one of the most important factors for KRD classification (Xiong et al. 2002; Huang and Cai 2009; Tong et al. 2013). FVC is a comprehensive quantitative indicator with which to describe the conditions of vegetation. In this study, a dimidiate pixel model, which is a simplified linear spectral unmixing method, was used to calculate the FVC (Zeng et al. 2000; Montandon and Small 2007). The model assumes a specific pixel contains only 


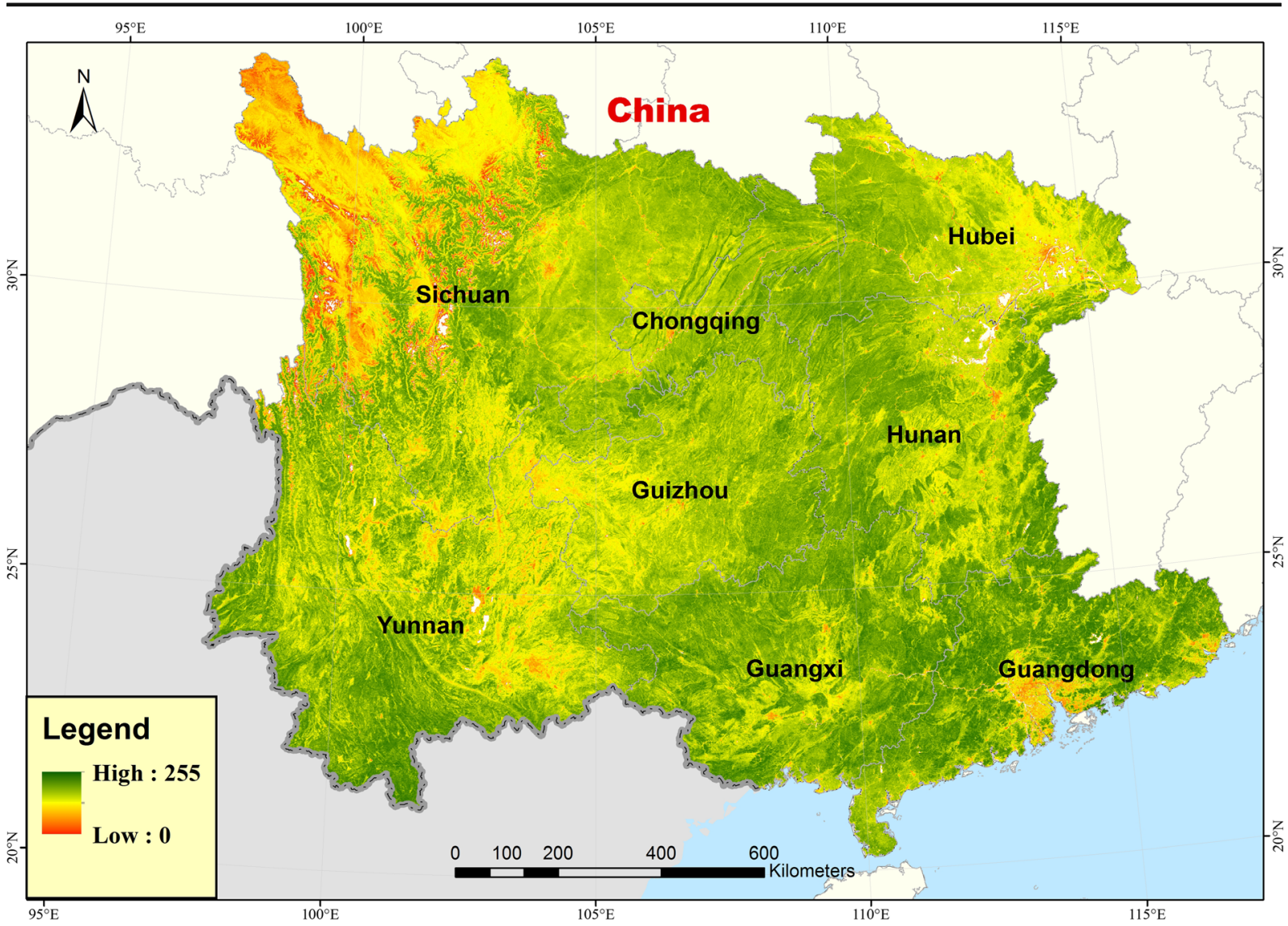

Fig. 3 The first PCA component FVC in 2010

two elements (vegetation and soil), which can be represented as follows:

$$
\mathrm{FVC}=\left(\mathrm{NDVI}_{-} \mathrm{NDVI}_{\text {soil }}\right) /\left(\mathrm{NDVI}_{\mathrm{veg}}-\mathrm{NDVI}_{\text {soil }}\right),
$$

where NDVI represents the Savitzky-Golay filtered results of the 250-m-resolution MODIS NDVI products. $\mathrm{NDVI}_{\text {soil }}$ and $\mathrm{NDVI}_{\mathrm{veg}}$ are the two key input parameters that represent the NDVI values of pure pixels of bare soil and vegetation, respectively. The selections of $\mathrm{NDVI}_{\text {soil }}$ and $\mathrm{NDVI}_{\mathrm{veg}}$ depended mainly on the land cover map of China, high spatial resolution data, hyperspectral images, and field samples. For different vegetation types, $\mathrm{NDVI}_{\text {veg }}$ represented the mean value of all pure vegetation pixels selected from the high spatial resolution data typical of the study area. NDVI soil $_{\text {was }}$ calculated based on pure soil pixels, which were detected from the hyperspectral imagery and compared with field spectral measurements. The detailed process of FVC calculation has been described by Lü et al. (2015).

\section{Principal component analysis}

In this study, MODIS Terra 16-day composite 250-m NDVI (MOD13Q1) data were used. Because of the high temporal resolution of the MODIS NDVI data, three NDVI images were acquired for each month (i.e., 36 NDVI images for 2010). The FVC was generated from each NDVI image and thus 36 FVC images were derived for 2010. These $36 \mathrm{FVC}$ images were highly correlated.

Interband correlation is a problem frequently encountered in the analysis of multispectral image data. That is, images generated by digital data from bands with various wavelengths often appear similar and convey partial information. Principal component analysis is a well-established feature extraction method, which is designed to decorrelate the data by transforming the digital number (DN) of pixel distributions around sets of new "multi-spaced" axes. Besides the capability of PCA to reduce the computational load, it often also diminishes some of the noise present in the original images. In this 


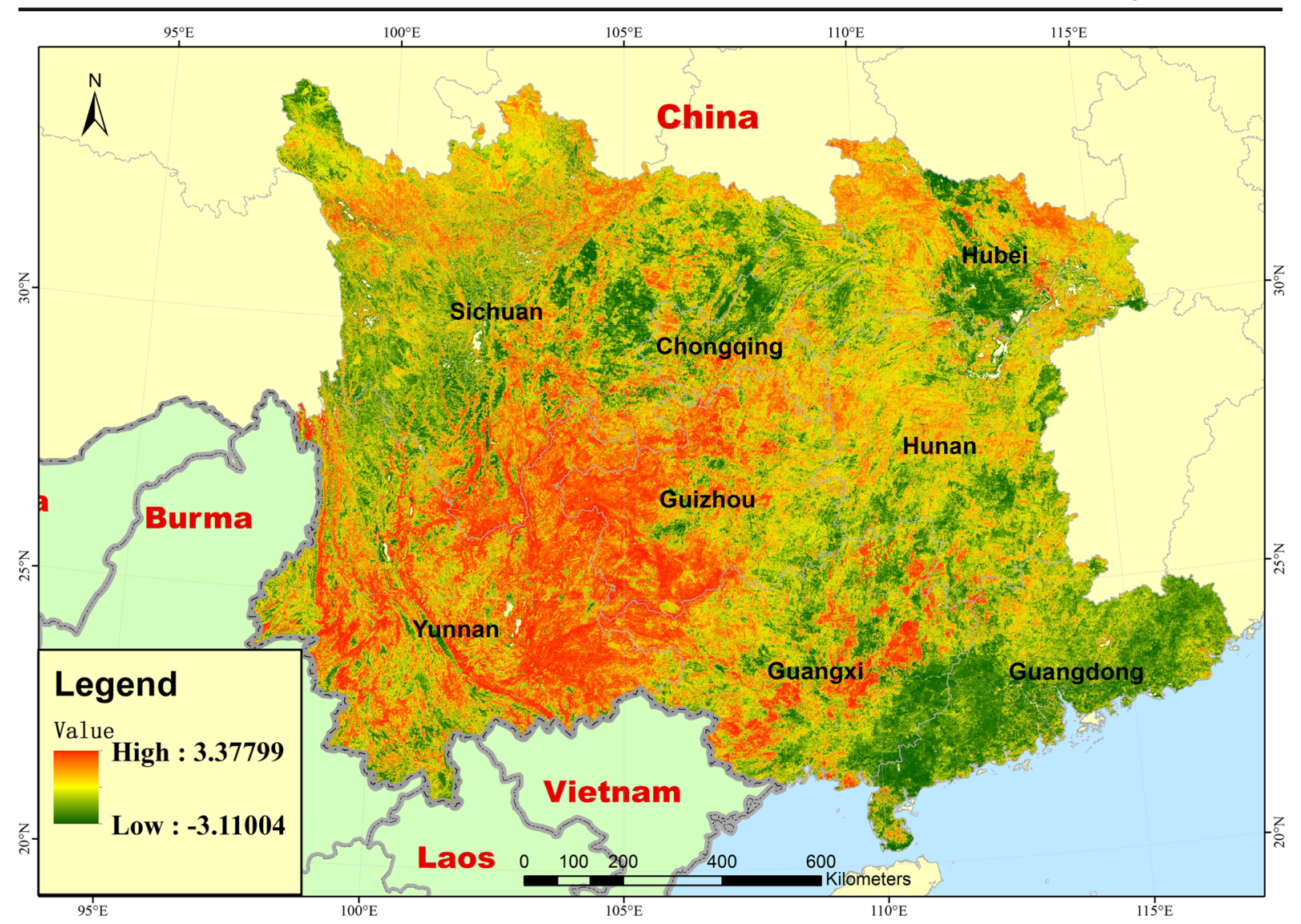

Fig. 4 Slope image of annual seasonal trend of FVC

study, PCA was performed to reduce the highly correlated $36 \mathrm{FVC}$ images and their mutually redundant information into three uncorrelated components.

\section{Annual seasonal trends analysis}

The Earth Trends Modeler (ETM), developed by Eastman et al. (2009), focuses on the analysis of trends and dynamic characteristics of phenomena evident in time series images. The ETM provides tools for determining the presence of trends that are both linear and monotonic (non-linear) as well as their significance (Eastman et al. 2013). In addition, the trend analysis tools ETM provides are resistant to the presence of outliers in short time series.

In order to analyze the annual seasonal trends of FVC, TS median trend analysis, which is a non-parametric estimator based on the median values of pairwise combinations, was used (Eastman 2015; Parmentier 2014). One important advantage of median trend statistics is that they are less affected by outliers (Neeti and Eastman 2011; Neeti et al. 2012; Peng et al. 2012b; Parmentier 2014). An ordinary least squares (OLS) estimate, based on the least error sum of the squares between predicted and observed values, provides a reference value of the trend analysis of time series data (Eastman et al. 2009; Hou et al. 2015). However, OLS is strongly affected by outliers. The slope image produced by the TS median trend analysis is often identical to OLS output when long time series are used. However, for short time series data, the results can be different, and the former procedure is generally considered more reliable (Eastman 2015). Therefore, the TS median trend analysis has been incorporated into ETM in the IDRISI TerrSet software packages.

\section{KRD classification}

Previous studies have proposed a standard for classifying the level of KRD (Xiong et al. 2002; Huang and Cai 2009; Tong et al. 2013). Based on vegetation coverage, slope, bedrock exposure, depth of surface soil, and remote sensing image color Xiong et al. (2002) divided 
KRD into four levels: none, slight, moderate, and severe (Table 1). In addition, Tong et al. (2013) have divided $\mathrm{KRD}$ into four levels based only on vegetation coverage and bedrock exposure (Table 2). This study also adopted four levels of KRD classification.

In this study, the K-means clustering method was used to classify KRD in descending ranked zones (or levels). Multiple data including PCA components, slope of seasonal trends, and incidence of KRD for each rock type were used as inputs in the K-means clustering analysis. The K-means clustering technique groups pixels with similar spectral response patterns into one cluster and partitions an $\mathrm{n}$-dimensional image into $\mathrm{K}$ exclusive clusters. To quantify pixel similarity, Euclidean distance measures in multispectral space were used (Richards and Jia 2006). K-means clustering begins by randomly initializing $\mathrm{K}$ centroids (means). It then assigns each pixel to the cluster whose centroid is nearest or most similar (in one dimension in this case), updates the cluster centroids, and repeats the process until the $\mathrm{K}$ centroids are fixed. Additional details regarding the $\mathrm{K}$-means algorithm for remote sensing image classification can be found in Richards and Jia (2006).

Because the performance of the algorithm depends strongly on the initial estimate of the partition, a relatively large numbers of clusters are generally recommended to acquire an initial pattern of centroids that is as complete as possible (Richards and Jia 2006). In practice, the actual or optimum number of clusters is not known when using clustering to perform unsupervised classification. However, if the specified number is too large, it will take a long time to classify and merge

Table 1 Standard KRD levels (or classes) after Xiong et al. (2002)

\begin{tabular}{|c|c|c|c|}
\hline \multirow[b]{2}{*}{ Indicator } & \multicolumn{3}{|c|}{ KRD standard } \\
\hline & $\begin{array}{l}\text { Slight } \\
\text { KRD }\end{array}$ & $\begin{array}{c}\text { Moderate } \\
\text { KRD }\end{array}$ & $\begin{array}{l}\text { Severe } \\
\text { KRD }\end{array}$ \\
\hline $\begin{array}{l}\text { Percentage of vegetation } \\
\text { cover }(\%)\end{array}$ & $50-70$ & $30-50$ & $<30$ \\
\hline Slope degree $\left(^{\circ}\right)$ & $>18$ & $>22$ & $>25$ \\
\hline $\begin{array}{l}\text { Percentage of exposed } \\
\text { bedrock }(\%)\end{array}$ & 96.2 & 67.8 & 75.7 \\
\hline $\begin{array}{l}\text { Average depth of topsoil } \\
\quad(\mathrm{cm})\end{array}$ & $<15$ & $<10$ & $<5$ \\
\hline $\begin{array}{l}\text { Color of the remote sensing } \\
\text { image }^{\mathrm{a}}\end{array}$ & $\begin{array}{l}\text { Green in } \\
\text { red }\end{array}$ & Gray in red & $\begin{array}{l}\text { White, } \\
\text { gray }\end{array}$ \\
\hline
\end{tabular}

Source: Huang and Cai (2007)

${ }^{\mathrm{a}}$ Landsat TM image false color composite (bands 4, 3, 2)
Table 2 Standard KRD levels (or classes) after Tong et al. (2013)

\begin{tabular}{lll}
\hline KRD levels & $\begin{array}{l}\text { Percentage of exposed } \\
\text { bedrock (\%) }\end{array}$ & $\begin{array}{l}\text { Percentage of vegetation } \\
\text { cover }(\%)\end{array}$ \\
\hline None & $<30$ & $>70$ \\
Low & $30-50$ & $50-70$ \\
Moderate & $50-70$ & $30-50$ \\
High & $>70$ & $<30$ \\
\hline
\end{tabular}

the clusters. Conversely, if too few clusters are chosen initially, then some multimodal classes (or clusters) will be formed, reducing the ultimate classification accuracy (Richards and Jia 2006). In this study, $K$ was first input as 15 , and each cluster (land unit) was given a descending rank order by assigning a value of one to the unit with the highest suitability value, a value of two to the second most suitable unit, and so on. When clustering is completed, the clusters can be examined to see whether any contain so few points as to be meaningless, or whether some clusters represent unnecessary divisions of the data and therefore should be merged (Lillesand et al. 2004; Richards and Jia 2006).

\section{Assessment of KRD classification}

Accuracy assessment is important for understanding the obtained results and for their interpretation within a decision-making context. One KRD map in Wenshan Prefecture, Yunnan Province was made in our previous study; it was produced using an MCE approach by integrating Landsat TM data with GIS (Zhang et al. 2014). This map was used as validation data with which to evaluate the results of the KRD map produced by combining MODIS NDVI with annual seasonal trends and carbonate rock data in this study.

Congalton and Green (1999) prepared a thorough overview of the principles and practices in use for assessing classification accuracy. Foody (2002) also reviewed accuracy assessment for the classification of single-date remote sensing data, and discussed several specific issues related to accuracy assessment. One of the methods most commonly used for assessing image classification is the error matrix. In this study, classification accuracy was assessed using confusion or error matrices and Kappa statistics (Congalton and Green 1999). In addition, the agreements and disagreements in quality and location of grid cells between the two maps were measured using a validation module proposed by Pontius 
(2000). This validation module analyzes quantification error versus location error in a comparison between two cellular maps that show a categorical variable (Pontius 2000). The positional accuracy measures can provide the information of agreement/disagreement between classification and reference maps due to (1) chance, (2) quantity, or (3) location at the grid cell level (Pontius 2000).

\section{Results}

Annual seasonal trends analysis

The PCA results show that the first component explains $69.27 \%$ of the variance, and the second and third components explain 16.38 and $6.11 \%$, respectively. Overall, the FVC variance explained by the first three components is $91.69 \%$. Moreover, PCA1 clearly shows the spatial pattern of vegetation cover within the study region (Fig. 3). The PCA value is low in the northwest of the study area (at the junction of Yunnan Province,
Sichuan Province, and Tibet), which is a region where the elevation is high and land cover is dominated by alpine talus, meadow, and shrubs. In addition, the PCA1 value at the Pearl River delta, as well as at the border of Yunnan, Guizhou, and Guangxi provinces is low.

As mentioned before, TS median trend analysis was used to analyze the annual seasonal trends of FVC. The slope image of the annual seasonal trends is shown in Fig. 4. It can be seen that the high slope values (red) occur at the junction of Yunnan, Sichuan, and Guizhou provinces where karst mainly occurs there (Fig. 1). The lower values are mainly found in the Sichuan basin, Hubei and Hunan border in the Yangtze River basin, and Pearl River Delta region (Fig. 4).

\section{KRD mapping}

\section{KRD assessment based on FVC}

The mean FVC was produced from the $36 \mathrm{FVC}$ images (Fig. 5). It shows that the lower FVC occurs mainly in

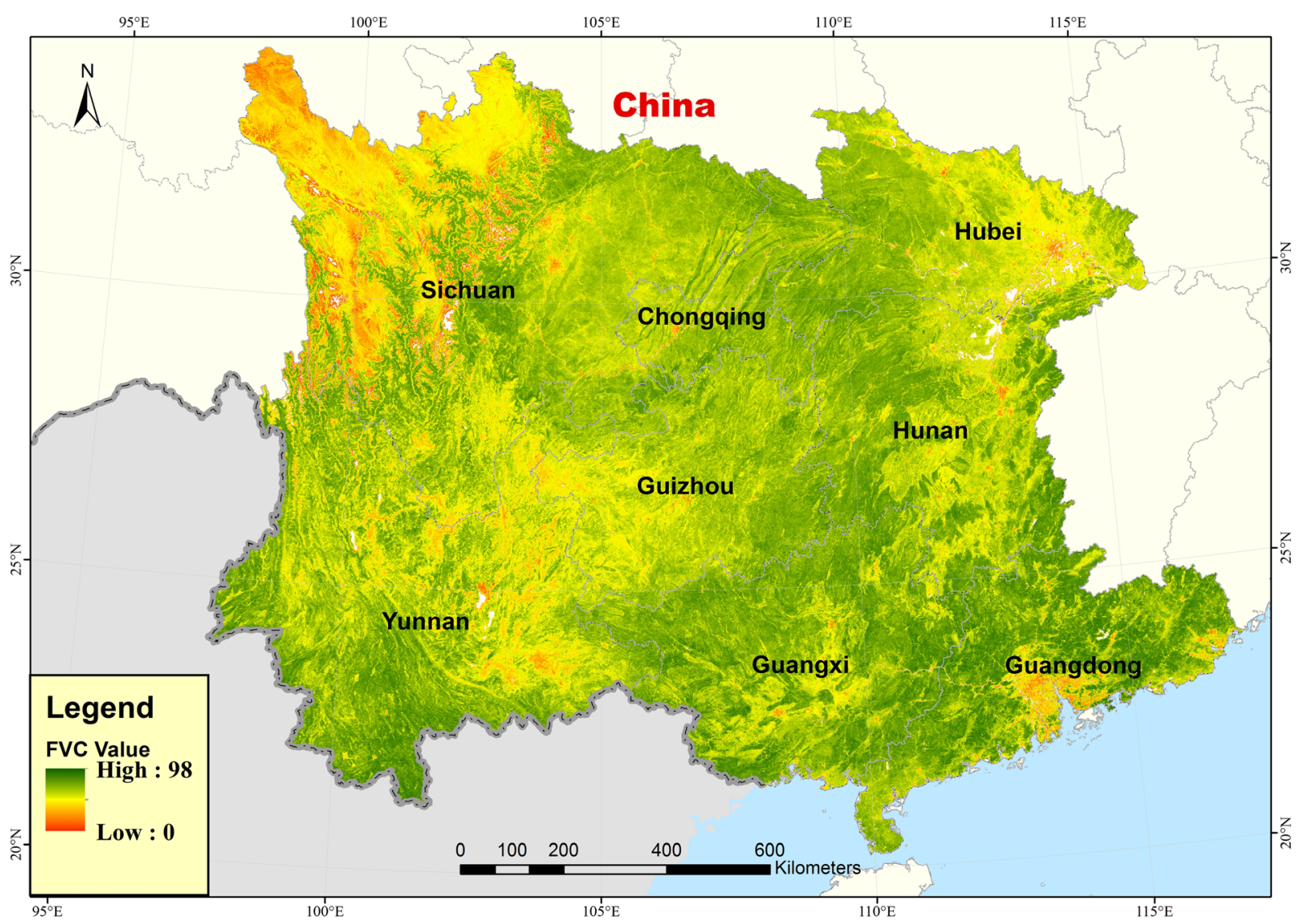

Fig. 5 Mean FVC in 2010 
the alpine area located in Yunnan, Sichuan, and Tibet, as well as in adjacent areas of Yunnan, Guizhou, and Guangxi provinces (Fig. 5). In addition, the KRD map was obtained based on the KRD levels identified by the FCV values in Table 2 (Fig. 6). After overlaying the slope, elevation, and carbonate rock map, a final KRD map based on FVC was generated (Fig. 7). This KRD map shows that the total area of KRD is $251.030 \times 10^{3} \mathrm{~km}^{2}$, which comprises $12.90 \%$ of the eight southwestern provinces of China. The biggest area is low KRD, which covers $224.22 \times 10^{3} \mathrm{~km}^{2}$ and comprises $89.32 \%$ of the total KRD area. The area of moderate KRD is $25.66 \times 10^{3} \mathrm{~km}^{2}$, which comprises $10.22 \%$ of the total KRD area. The area of high KRD covers only $1.15 \times 10^{3} \mathrm{~km}^{2}$ (Table 3 ). KRD occurs mainly in Guizhou and Yunnan provinces. Moreover, the KRD incidence rate (KRD area/total karst area) is $>20 \%$ in all provinces, peaking at $>60 \%$ in Guizhou Province (Table 4). The KRD area in Guizhou Province is $72.54 \times 10^{3} \mathrm{~km}^{2}$ (Table 4), which comprises $41.22 \%$ of the total land area of the province. However, this is considered an overestimate based on field survey.

\section{KRD mapping based on PCA and ASTA}

KRD was mapped with four descending ranked levels using K-means clustering analysis where the PCA components, integrated with the slope of annual seasonal trends and incidence of KRD for each rock type, were used as inputs (Fig. 8). The areas and percentages of each KRD classes are shown in Table 5.

The PCA and seasonal trend analysis results indicate that KRD occurs mainly in Guizhou, Yunnan, and $\mathrm{Hu}-$ nan provinces (Fig. 8). Table 6 shows that the highest KRD incidence rate (KRD area/total karst area) is $27.42 \%$ in Yunnan Province, followed by Guizhou and Guangxi provinces (23.08 and $14.07 \%$, respectively); for all other provinces, the $\mathrm{KRD}$ rate is $<10 \%$.

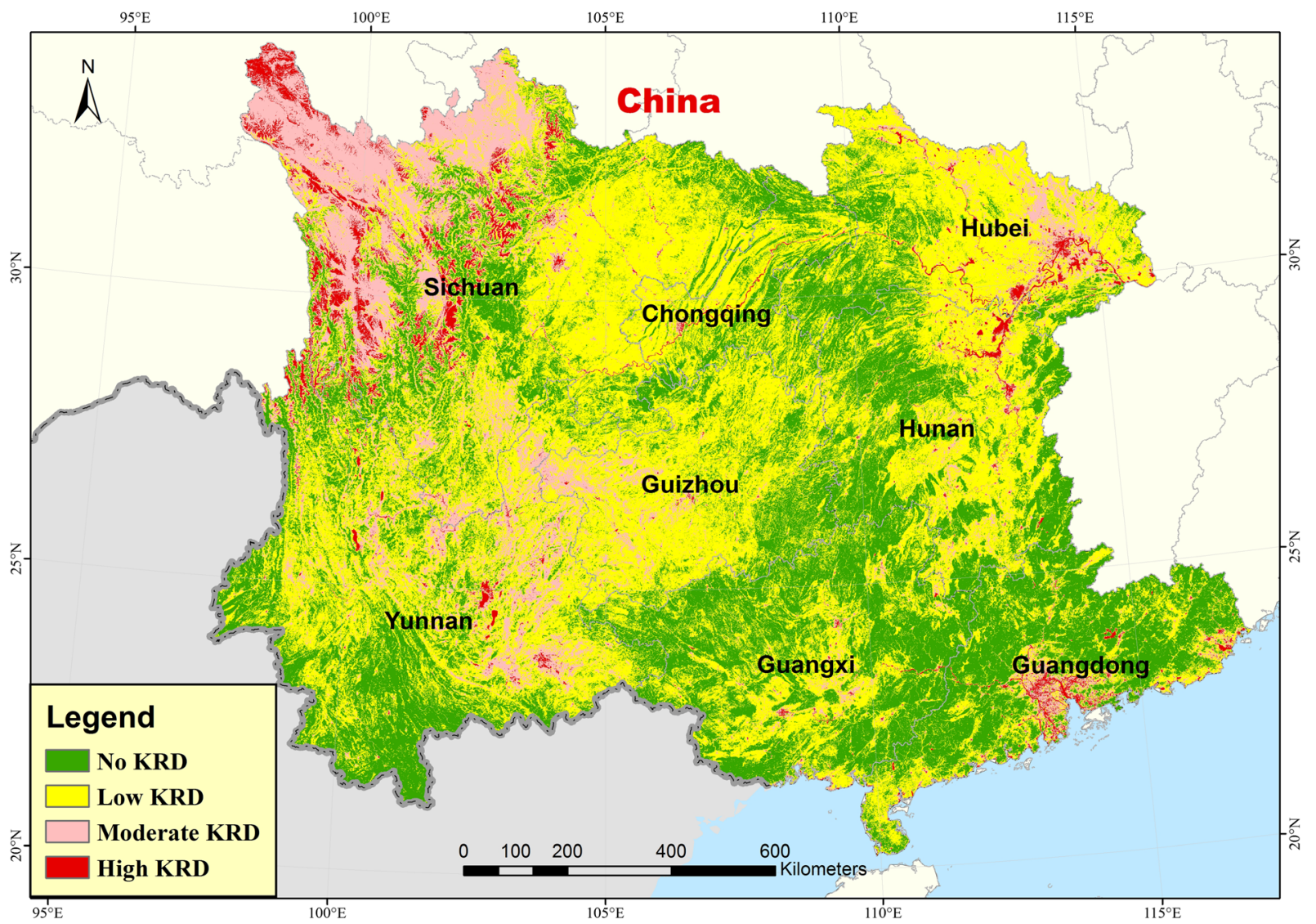

Fig. 6 KRD assessment derived from the mean FVC based on the standards of Table 4 (Tong et al. 2013) 


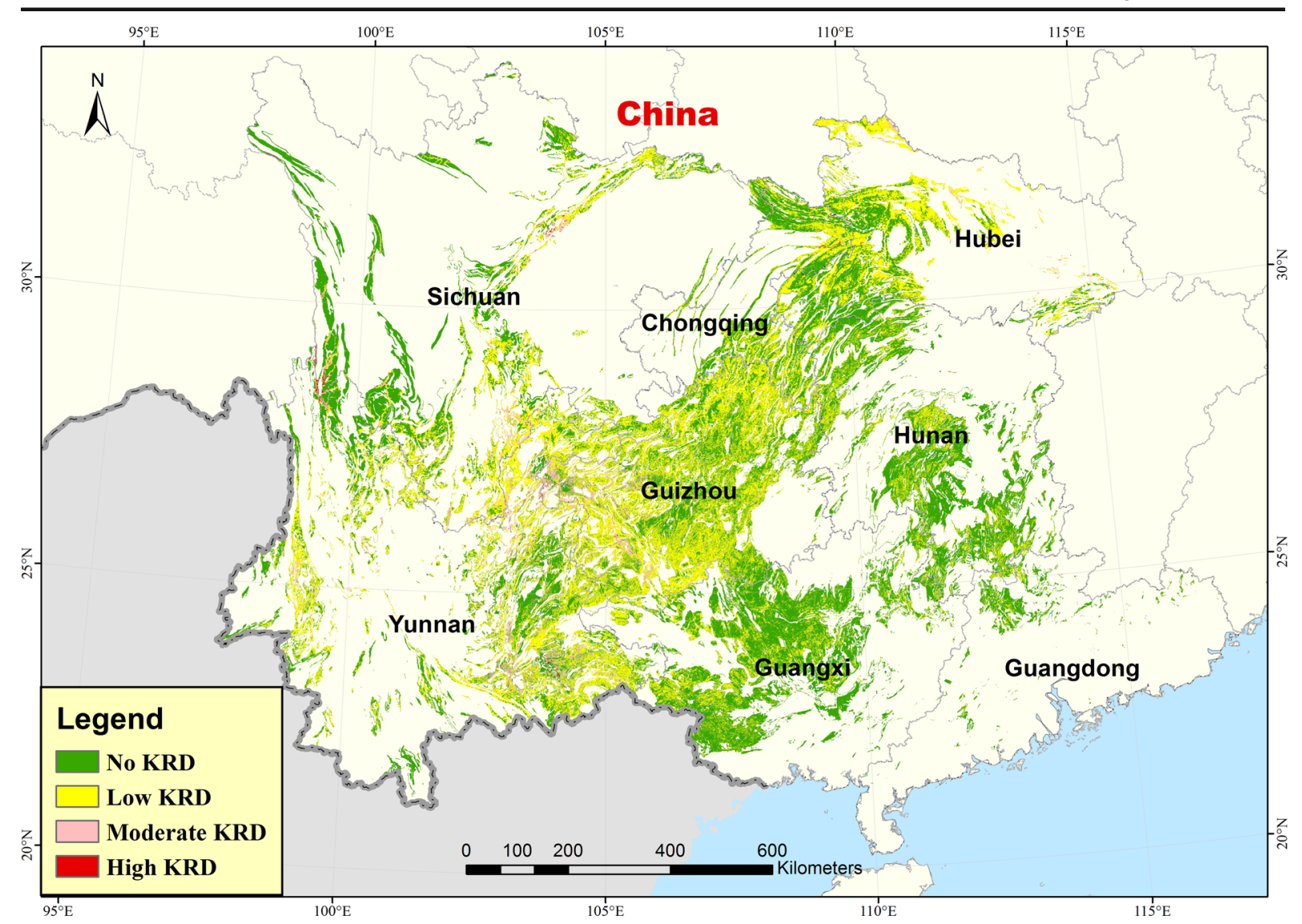

Fig. 7 KRD assessment map derived by overlaying the mean FVC with carbonate rock types, slope $<5^{\circ}$, and elevation $>3300 \mathrm{~m}$

Accuracy assessment

As mentioned in "Materials and methods" (KRD classification) section, the map of KRD in Wenshan Prefecture, Yunnan Province, created in our previous work (Zhang et al. 2014), was used to evaluate the accuracy of the KRD maps generated in this study. The KRD areas generated by FVC are much larger than those in the other two maps (Fig. 9). Based on visual evaluation, the KRD map created using PCA in combination with ASTA has greater similarity with the map generated

Table 3 KRD classes derived using the standards of Tong et al. (2013)

\begin{tabular}{lcc}
\hline KRD level & Area $\left(\times 10^{3} \mathrm{~km} 2\right)$ & Percentage of total KRD $(\%)$ \\
\hline Low & 224.22 & 89.32 \\
Moderate & 25.66 & 10.22 \\
High & 1.15 & 0.46 \\
Total & 251.03 & \\
\hline
\end{tabular}

using the MCE method than the map derived by mean FVC (Fig. 9a, c). In addition, the Kappa value is 0.6365 ,

Table 4 KRD classes in eight provinces derived from mean FCV based on the standards of Tong et al. (2013)

\begin{tabular}{lccc}
\hline Province & $\begin{array}{l}\text { KRD area } \\
\left(\times 10^{3} \mathrm{~km} 2\right)\end{array}$ & $\begin{array}{l}\text { KRD incidence rate } \\
\text { (KRD area/total karst } \\
\text { area in the province) } \\
(\%)\end{array}$ & $\begin{array}{l}\text { Percentage of } \\
\text { KRD area in } \\
\text { each province } \\
(\%)\end{array}$ \\
\hline Sichuan & 30.45 & 42.07 & 6.27 \\
Yunnan & 63.26 & 58.52 & 16.51 \\
Guizhou & 72.54 & 62.70 & 41.22 \\
Guangxi & 22.29 & 26.90 & 9.43 \\
Hunan & 17.88 & 27.36 & 8.43 \\
Hubei & 29.61 & 55.99 & 15.92 \\
Chongqing & 13.35 & 43.72 & 16.20 \\
Guangdong & 1.65 & 20.87 & 0.94 \\
Total & 251.03 & $46.86(251.03 /$ & 12.95 \\
& \multicolumn{3}{c}{$535.74)$} \\
\hline
\end{tabular}




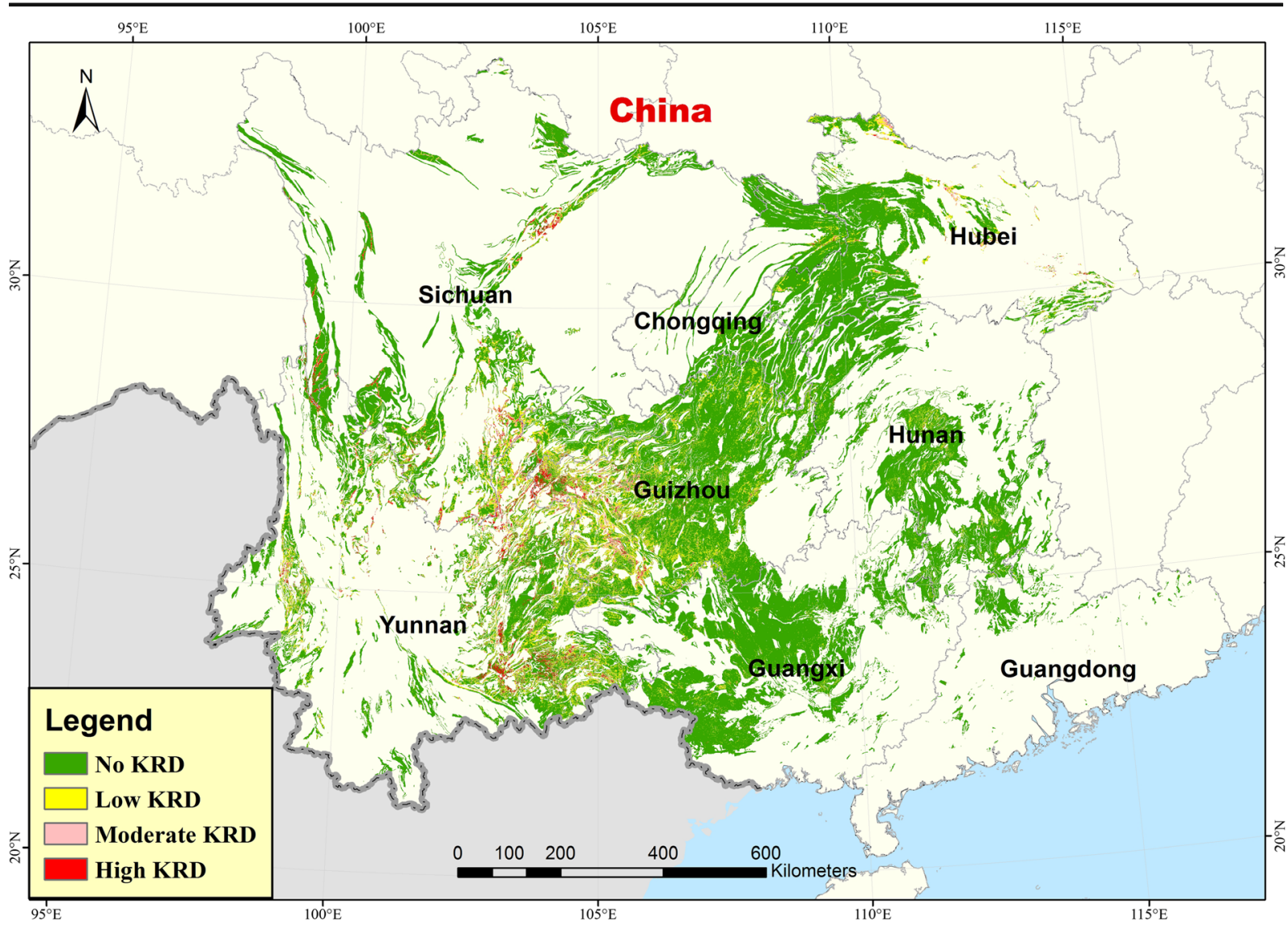

Fig. 8 KRD assessment map derived by combining PCA and ASTA, and overlaying with carbonate rock types, slope $<5^{\circ}$, and elevation $>3300 \mathrm{~m}$

and the grid cell agreement is $43.97 \%$, which is much higher than generated by the mean FVC (Table 7).

\section{Discussion}

In this study, the annual seasonal trends of vegetation were combined with NDVI and other ancillary data for KRD assessment. The results showed clearly that KRD is overestimated when using the mean FVC based on the

Table 5 KRD classes derived using PCA and ASTA

\begin{tabular}{lcc}
\hline KRD level & Area $\left(\times 10^{3} \mathrm{~km} 2\right)$ & Percentage of total KRD $(\%)$ \\
\hline Low & 49.72 & 63.13 \\
Moderate & 21.17 & 26.88 \\
High & 7.87 & 9.99 \\
Total & 78.76 & \\
\hline
\end{tabular}

vegetation coverage standard proposed in Table 2 . The KRD classification map derived by PCA in combination with the ASTA approach has higher accuracy than

Table 6 KRD classes in eight provinces derived from combining PCA with ASTA and ancillary data

\begin{tabular}{lccc}
\hline Province & $\begin{array}{l}\text { KRD area } \\
\left(\times 10^{3} \mathrm{~km}^{2}\right)\end{array}$ & $\begin{array}{l}\text { KRD incidence rate } \\
\text { (KRD area/total karst } \\
\text { area in the province }) \\
(\%)\end{array}$ & $\begin{array}{l}\text { Percentage of } \\
\text { KRD area in } \\
\text { each province } \\
(\%)\end{array}$ \\
\hline Sichuan & 2.74 & 3.78 & 0.56 \\
Yunnan & 29.64 & 27.42 & 7.73 \\
Guizhou & 26.70 & 23.08 & 15.17 \\
Guangxi & 11.66 & 14.07 & 4.93 \\
Hunan & 2.91 & 4.45 & 1.37 \\
Hubei & 3.44 & 6.51 & 1.85 \\
Chongqing & 1.51 & 4.95 & 1.83 \\
Guangdong & 0.16 & 2.03 & 0.09 \\
Total & 78.76 & $14.70(78.76 / 535.74)$ \\
\hline
\end{tabular}




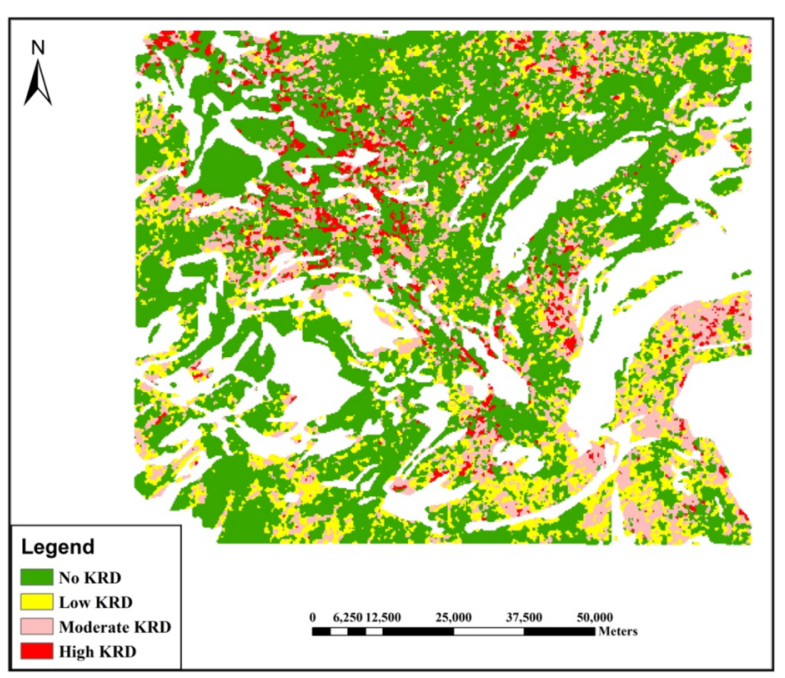

(a)

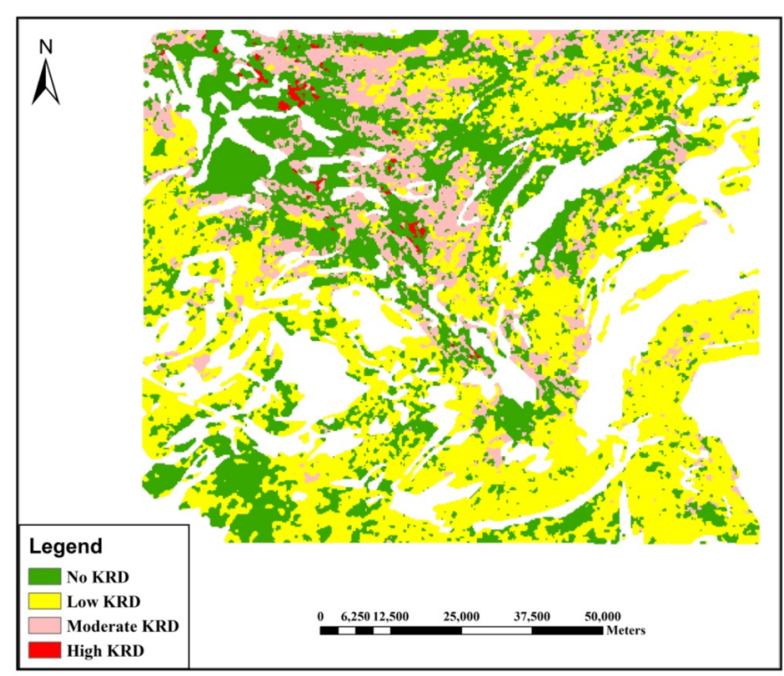

(b)

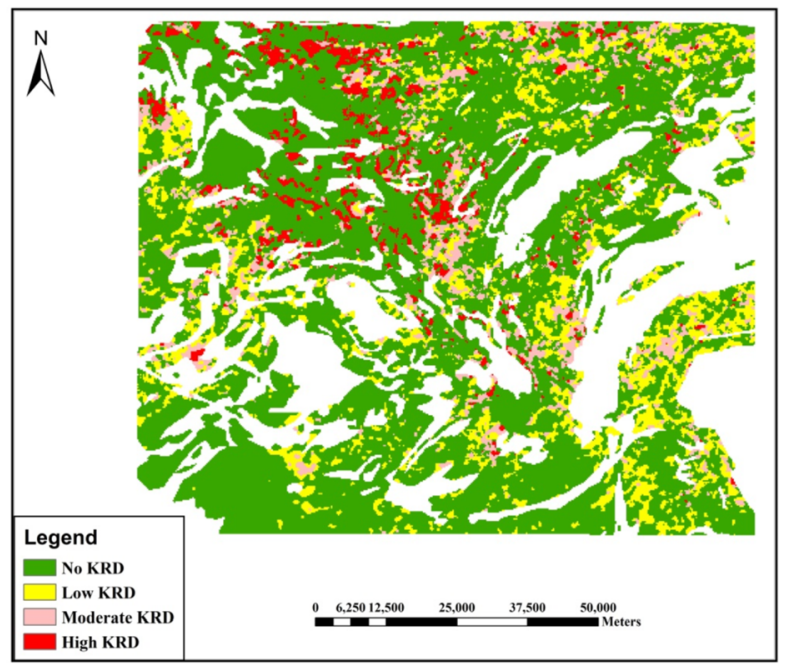

(c)

Fig. 9 KRD maps derived by three different methods. a KRD map derived from Landsat image data using the MCE approach (Zhang et al. 2014). b KRD map derived by mean FVC with the

obtained using the mean FVC method.

Based on Landsat TM imagery, Tong et al. (2013) reported that the total area of KRD in the eight provinces of southwestern China in 2008 was $70,000 \mathrm{~km}^{2}$. A bulletin published by The State Forestry Administration indicated that KRD in southwestern China was about $120,000 \mathrm{~km}^{2}$ by the end of 2011 (The State Forestry Administration 2012) (Table 8). The large area and high heterogeneity of KRD in southwestern China may have contributed to different findings for KRD area among studies standards of Tong et al. (2013). c KRD map derived by combining PCA with ASTA, and ancillary data

using different investigation and assessment methods. Even though this study finds a much larger KRD area $\left(251.03 \times 10^{3} \mathrm{~km}^{2}\right)$ than previous studies, the area of KRD $\left(78.76 \times 10^{3} \mathrm{~km}^{2}\right)$ derived using the combination of PCA and the TSTA approach is similar to previous findings (Tong et al. 2013; The State Forestry Administration, 2012). Thus, this study demonstrates that the integration of PCA and the annual seasonal trend approach is more effective than the mean FVC approach for KRD mapping. 
Table 7 Agreement between the KRD map of Wenshan Prefecture derived from Landsat image data using the MCE approach (Zhang et al. 2014) and KRD map derived by mean FVC with the standards of Tong et al. (2013) and by combining PCA with annual seasonal trends, and ancillary data

\begin{tabular}{lll}
\hline $\begin{array}{l}\text { Agreement } \\
\text { index }\end{array}$ & $\begin{array}{l}\text { KRD map derived by } \\
\text { mean FVC according to } \\
\text { the standards of Tong } \\
\text { et al. (2013) }\end{array}$ & $\begin{array}{l}\text { KRD map derived by } \\
\text { combining PCA with } \\
\text { ASTA, and ancillary data }\end{array}$ \\
\hline $\begin{array}{c}\text { Kappa } \\
\text { value } \\
\begin{array}{c}\text { Grid cell } \\
\text { agree- } \\
\text { ment }\end{array}\end{array}$ & 0.5374 & 0.6365 \\
\hline
\end{tabular}

The karst landscapes of southwestern China, especially in Yunnan, Guizhou, and Guangxi provinces, are typical of present-day subtropical areas. These areas are affected greatly by the southwest monsoon, and the dry season generally begins at the end of October and ends at the end of May. The red part in the slope map of the annual seasonal trend of FVC is where the vegetation coverage first increases and then decreases, forming a unimodal (summer) mode; however, the overall trend is upward (Figs. 5 and 10a). Most of the vegetation coverage is shrubs, dominated by Rosaceae and Ericaceae species, which are evergreen. However, before the onset of the rainy season in March and April, the leaves of

Table $8 \mathrm{KRD}$ areas in each of eight provinces of southwestern China derived by Tong et al. (2013), The State Forestry Administration (2012), and by combining PCA with TSTA and ancillary data in this study

\begin{tabular}{lcll}
\hline Province & $\begin{array}{l}\text { KRD in 2008 } \\
(\text { Tong et al. } \\
2013) \\
\left(\times 10^{3} \mathrm{~km}^{2}\right)\end{array}$ & $\begin{array}{l}\text { KRD in 2011 } \\
\text { (The State } \\
\text { Forestry } \\
\text { Administration, } \\
2012)\left(\times 10^{3} \mathrm{~km}^{2}\right)\end{array}$ & $\begin{array}{l}\text { KRD in 2010 } \\
\text { obtained in this } \\
\text { study }\left(\times 10^{3} \mathrm{~km}^{2}\right)\end{array}$ \\
\hline Sichuan & 2.15 & 7.32 & 2.74 \\
Yunnan & 20.11 & 28.40 & 29.64 \\
Guizhou & 20.94 & 30.24 & 26.70 \\
Guangxi & 17.03 & 19.26 & 11.66 \\
Hunan & 3.32 & 14.31 & 2.91 \\
Hubei & 2.64 & 10.91 & 3.44 \\
Chongqing & 2.35 & 8.95 & 1.51 \\
Guangdong & 1.474 & 0.64 & 0.16 \\
Total & 70.02 & 120.03 & 78.76 \\
\hline
\end{tabular}

many other plant species drop, which leads to the lowest value for FVC (Figs. 4 and 10a). Figure 10b also shows a unimodal pattern in the yellow areas. This indicates that vegetation coverage begins to increase in March and reaches its highest value in August. Coverage then drops quickly to its lowest value in autumn and winter. This seasonal trend likely reflects the annual growth pattern of herbs and crops. The green area is located in one national nature reserve in Wenshan Prefecture, Yunnan Province, which is dominated by evergreen broadleaved and mixed coniferous forests. As a result, the seasonal vegetation coverage change is not dramatic (Fig. 10c). Figure 10d indicates the Dianchi Lake in the Yunnan Province, where the FVC value is zero. Figure 10e shows that the highest vegetation coverage occurs in spring between March and April. Conversely, the lowest vegetation coverage occurs in summer from July to September. This trend likely reflects wetland areas that are flooded by summer rainfall or irrigation water. It is found mainly in the Sichuan basin, Hubei and Hunan border in the Yangtze River basin, and Pearl River Delta region (Figs. 4 and 10e). The slope image of annual FVC seasonal trend indicates that KRD likely occurs in the red and yellow areas. Therefore, this slope image, integrated with PCA components and carbonate rock map, can improve the accuracy of KRD mapping.

The limitations of conventional image classification methods for accurate mapping of KRD have been summarized by Huang and Cai (2009). Previous studies have also reported that land cover in karst areas is often mixed (Xia et al. 2006; Yue et al. 2010), and that the spectral characteristics of built-up areas and karst rock are similar (Huang and Cai 2009). These problems limit the application of image classification approaches in karst regions. Moreover, the quality of the training data (i.e., the number of training samples representing each spectral class) is also highly critical for image classification (Lillesand et al. 2004; Lu and Weng 2007). For the large, highly heterogeneous karst landscape of southwestern China, it is very difficult to collect sufficient ground truth training data for each KRD class.

In practice, prior to using image classification methods to map or assess KRD, it is important to define or classify the different levels (or classes) of KRD and to select the appropriate KRD classification standard. However, how best to achieve this remains debatable. Although Xiong et al. (2002) and Huang and Cai (2007) proposed a standard for classifying KRD in Guizhou 

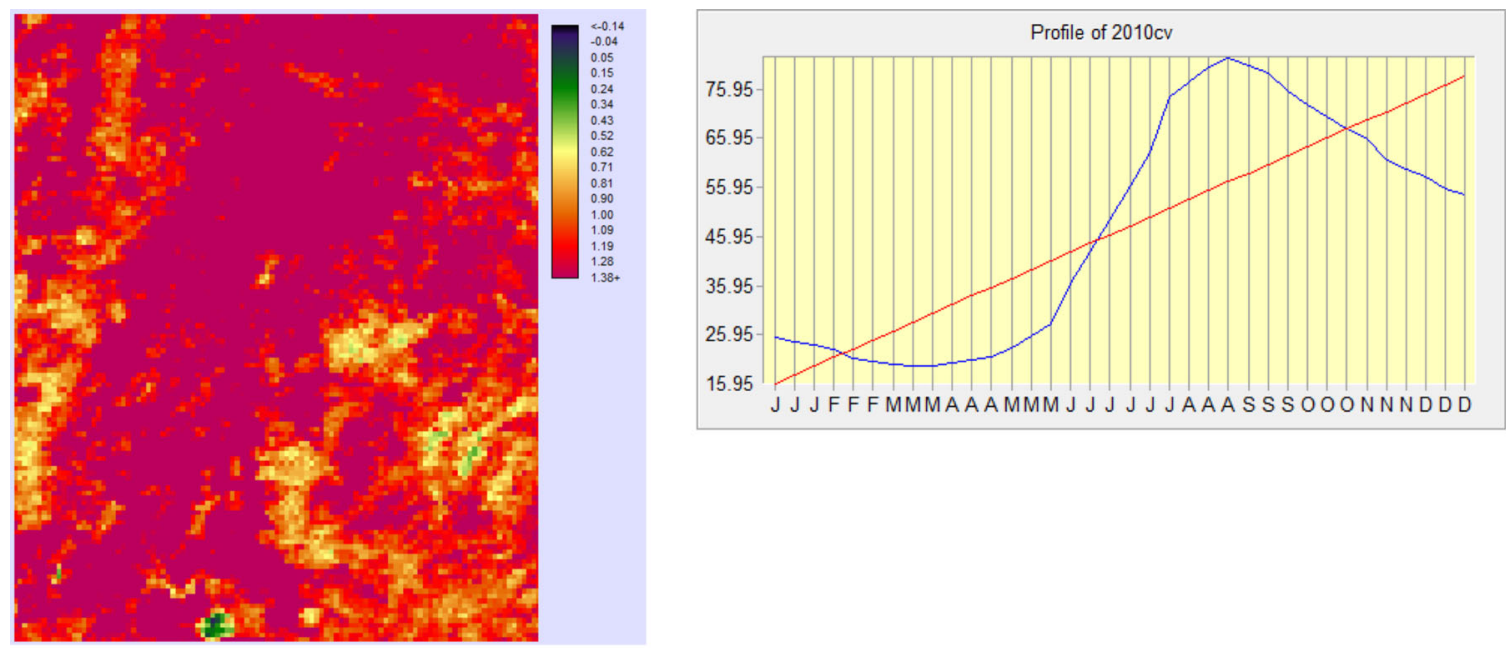

(A) Red areas mean high slope values of annual seasonal vegetation trends
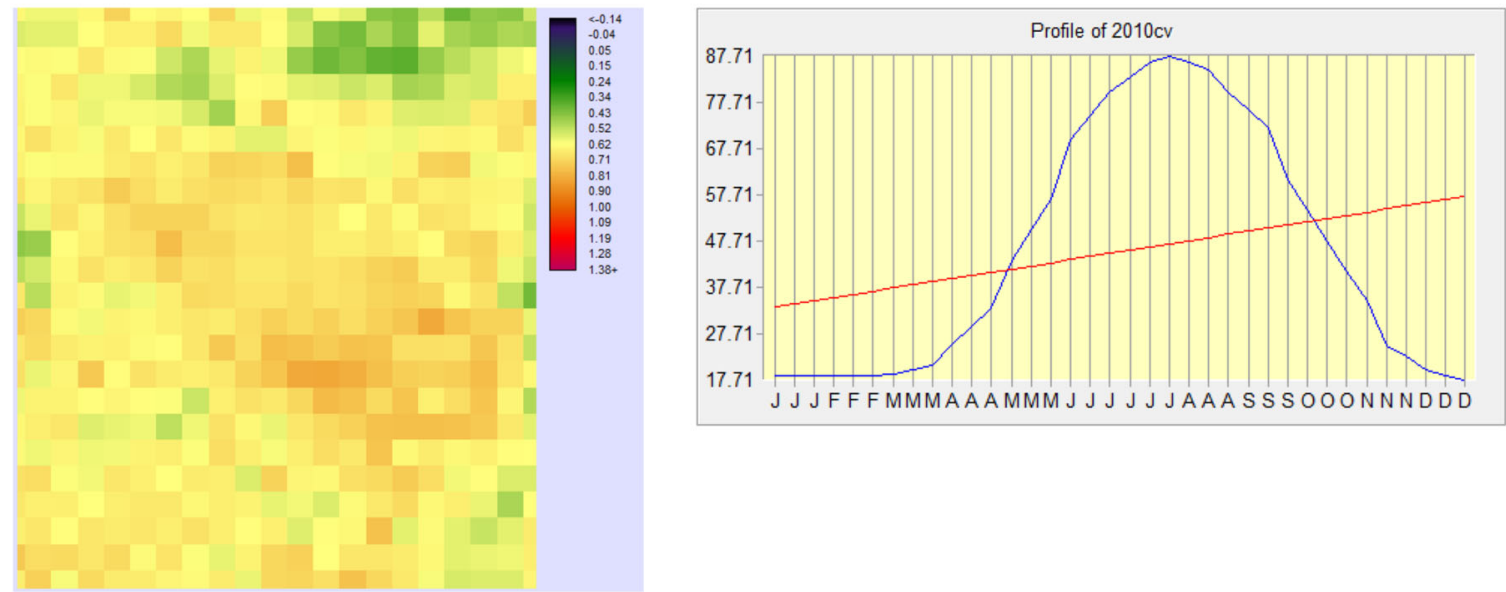

(B) Yellow areas mean low slope values of annual seasonal vegetation trends
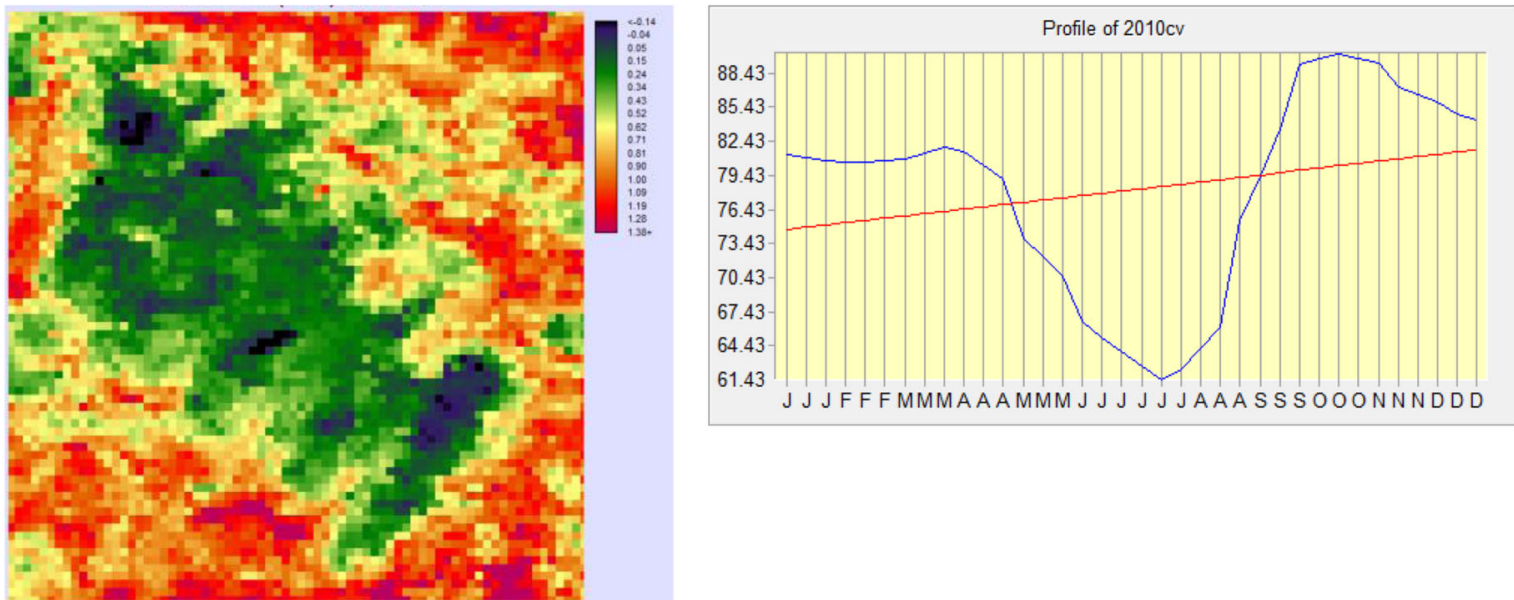

(C) Green area is a nature reserve with evergreen broadleaf and needle leaf forests

Fig. 10 Annual FVC seasonal trend of different land cover types 

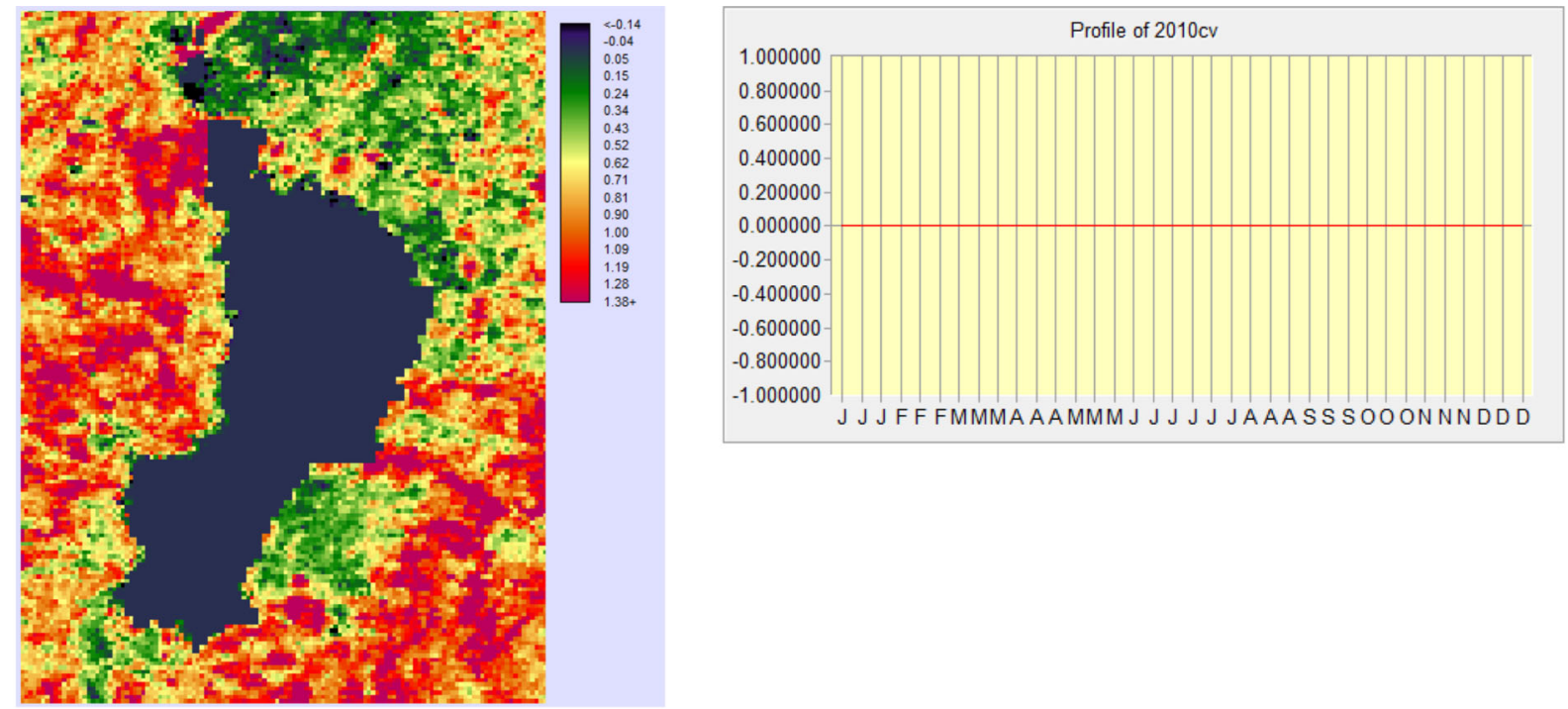

(D) Dark green area means annual FVC seasonal trend of Dianchi Lake
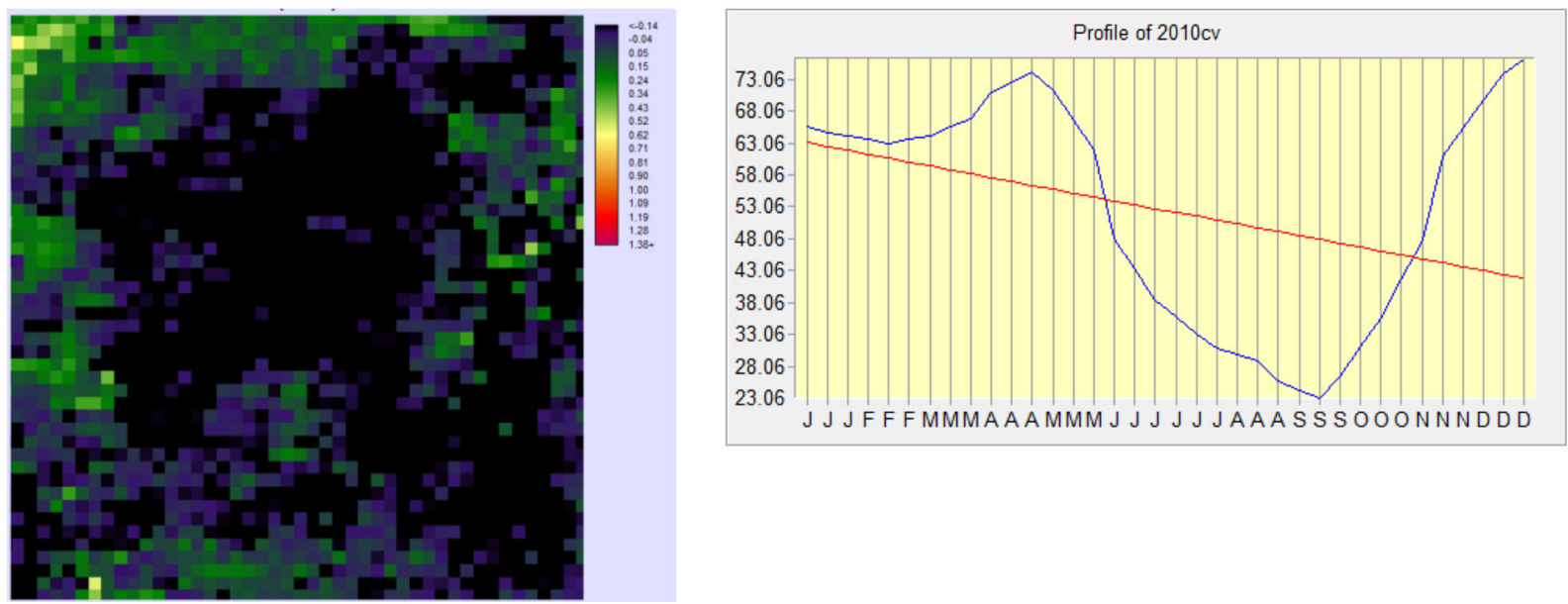

(E) Dark green means a negative slope of annual seasonal vegetation trends

Fig. 10 (continued)

Province (Table 1), their suggestion involved a combined index that is difficult to adopt in the large area of southwestern China.

In this study, an approach was proposed that integrates PCA with ASTA to map KRD. This approach addresses the problem in a structured way (Koschke et al. 2012) and therefore, data from diverse sources (vegetation and other environmental indices derived from remote sensing data, topographic drivers, and carbonate rock types) were applied in an aggregation framework for assessing or mapping KRD. This approach avoids the requirement of imposing certain standards or classes prior to performing the analysis. In this study, the K-means algorithm was used to cluster the PCA components, and the ASTA, topographic, and rock type data into four KRD classes or levels. Then, the KRD was assessed and evaluated using remote sensing data and other ancillary data (i.e., topographic and carbonate rock-type data). However, it is important to acknowledge the limitations of the available data and methods in this analysis. The specific challenges unique to remote sensing applications in karst mountain regions are well documented (climate, cloud, haze, and topographic shadows), and steep slopes make access difficult 
for fieldwork (Zhang et al. 2008; Weiss and Walsh 2009; Hou et al. 2015; Tong et al. 2016).

Previous studies have reported that human disturbance is also a very important factor in KRD. Therefore, human disturbance must be included in future versions of this combination approach. Accurately mapping and assessing KRD is important both for quantifying past changes and for predicting future changes. Accurate mapping and assessment can help develop sustainable planning and management practices to preserve essential ecosystem functions. Future work will also focus on KRD change detection and quantification.

\section{Conclusions and future work}

The annual seasonal dynamics of vegetation cover in karst regions are clear. The accuracy of a KRD map produced using PCA in combination with ASTA is greater than the accuracy obtained using the mean FVC according to the standards of Tong et al. (2013). This KRD map indicated that the total area of KRD of $78.76 \times 10^{3} \mathrm{~km}^{2}$ is $4.06 \%$ of the total land area of the eight southwestern provinces of China. This area is dominated by moderate and low KRD, which occur mainly in Guizhou, Yunnan, and Guangxi provinces. However, the results of this study show that the largest areas of KRD are found in Yunnan Province, not in Guizhou Province as reported in previous studies, and this requires further evaluation.

This study proposed an approach for KRD mapping that combines annual seasonal trends of vegetation with PCA and ancillary data. Overall, the pilot process performed well to generate a reasonable KRD map. Moreover, most previous KRD assessment studies have focused mainly on developing vegetation or land cover information in karst regions using remote sensing. It is also useful to integrate information on the annual seasonal change of vegetation, topography, and rock type into the mapping and assessment of KRD. Furthermore, the combined PCA and ASTA approach was demonstrated to be an easily implemented, robust, and flexible method that includes explicit quantitative and qualitative information. Here, a scientifically sound and practical approach for the mapping and assessment of KRD was presented, which could be used to enhance regional KRD management schemes or to address other environmental issues. Furthermore, it could be used for regional sustainable planning for development in China or in other developing countries that have similar environmental issues.

Acknowledgments This work was supported by a grant from the National Natural Science Foundation of China (41361046). The authors are grateful to Zhang Lu, Jiang Ling, Rao Enming, and Wang Liyan for their help during the fieldwork. We would like to thank Editage [www.editage.cn] and Mari McClelland for English language editing.

Author contributions All authors contributed significantly to this manuscript. To be specific, Zhiming Zhang, Weihua Xu, and Ouyang Zhiyun designed this study. Zhiming Zhang and Yang Xiao were responsible for the data processing. Zhiming Zhang wrote the draft with data analysis support from Yang Xiao.

\section{Compliance with ethical standards}

Conflict of interest The authors declare that they have no conflict of interest.

\section{References}

Adams, J. B., Sabol, D. E., Kapos, V., Filho, R. A., Roberts, D. A., Smith, M. O., \& Gillespie, A. R. (1995). Classification of multispectral images based on fractions of endmembers: application to land-cover change in the Brazilian Amazon. Remote Sensing of Environment, 52, 137-154.

Bao, G., Qin, Z., Bao, Y., Zhou, Y., Li, W., \& Sanjjav, A. (2014). NDVI-based long-term vegetation dynamics and its response to climate change in the Mongolian Plateau. Remote Sening., 6, 8337-8358.

Bou Kheir, R., Abdallah, C., \& Khawlie, A. (2008). Assessing soil erosion in Mediterranean karst landscapes of Lebanon using remote sensing and GIS. Engineering Geology, 99, 239-254.

Brinkmann, R., \& Parise, M. (2012). Karst environments: problems, management, human impacts, and sustainability, and introduction to the special issue. Journal of Cave and Karst Studies, 74(2), 135-136. doi:10.4311/2011JCKS0253.

Campo-Bescós, M. A., Muñoz-Carpena, R., Southworth, J., Zhu, L., Waylen, P. R., \& Bunting, E. (2013). Combined spatial and temporal effects of environmental controls on long-term monthly NDVI in the southern Africa Savanna. Remote Sensing, 5, 6513-6538.

Chen, Q. W., Lan, A. J., Xiong, K. N., Xiao, S. Z., Wang, J., \& Xiong, J. (2003). Spectral feature-based model for extracting karst rock desertification from remote sensing images. Journal of Guizhou Normal University (Natural Sciences), 21(4), 82-87 (in Chinese).

Congalton, R. G., \& Green, K. (1999). Assessing the accuracy of remotely sensed data: principles and practices. Boca Raton, FL: Lewis.

De Waele, J., Gutiérrez, F., Parise, M., \& Plan, L. (2011). Geomorphology and natural hazards in karst areas: a review. Geomorphology, 134, 1-8.

Drew, D., \& Hötzl, H. (1999). Karst Hydrogeology and Human Activities (p. 322). Rotterdam: Balkema. 
Drew, D. P. (1983). Accelerated soil erosion in a karst area: The Burren, western Ireland. Journal of Hydrology, 6, 113-124.

Eastman, J. R. (2015). IDRISI TerrSet Manual, 278-305p. Worcester: Clark University.

Eastman, J. R., Sangermano, F., Ghimire, B., Zhu, H., Chen, H., Neeti, N., Cai, Y., Machado, E. A., \& Crema, S. C. (2009). Seasonal trend analysis of image time series. International Journal of Remote Sensing, 30(10), 2721-2726.

Eastman, J. R., Sangermano, F., Machado, E. A., Rogan, J., \& Anyamaba, A. (2013). Global trends in seasonality of normalized difference vegetation index (NDVI), 1982-2011. Remote Sensing, 5, 4799-4818.

Foody, G. M. (2002). Status of land-cover classification accuracy assessment. Remote Sensing of Environment, 80, 185-201.

Ford, D. C., \& Williams, P. (2007). Karst Hydrogeology and Geomorphology (p. 563). Chichester: John Wiley.

Galford, G. L., Mustard, J. F., Melillo, J., Gendrin, A., Cerri, C. C., \& Cerri, C. E. P. (2008). Wavelet analysis of MODIS time series to detect expansion and intensification of row-crop agriculture in Brazil. Remote Sensing of Environment, 112, 576-587.

Gillieson, D., Wallbrink, P., \& Cochran, A. (1996). Vegetation change, erosion risk, and land management on the Nullarbor Plain, Australia. Environmental Geology, 28(3), 145-153.

Gunn, J. (2004). Limestone as a mineral resource. In J. Gunn (Ed.), Encyclopedia of caves and karst science (pp. 489-490). New York: Fitzroy Dearborn.

Hou, W., Gao, J., Wu, S., \& Dai, E. (2015). Interannual variations in growing-season NDVI and its correlation with climate variables in the southwestern karst region of China. Remote Sensing, 7, 11105-11124.

Hu, B. Q., Huang, Q. Y., Li, C. M., Yang, Z. Q., Jiang, S. F., \& Wu, Z. M. (2004). Spatial correlation analysis of karst rocky desertification and soil type based on RS and GIS. Bulletin of Soil and Water Conservation, 24(5), 67-70 (in Chinese).

Huang, Q. H., \& Cai, Y. L. (2006). Assessment of karst rocky desertification using the radial basis function network model and GIS technique: a case study of Guizhou province, China. Environmental Geology, 8, 1173-1179.

Huang, Q. H., \& Cai, Y. L. (2007). Spatial pattern of karst rock desertification in the middle of Guizhou Province, Southwestern China. Environmental Geology, 52, 13251330 .

Huang, Q. H., \& Cai, Y. L. (2009). Mapping karst rock in Southwest China. Mountain Research and Development, 29(1), 14-20.

Jiang, Z. Y., Huete, A. R., Chen, J., Chen, Y. H., Li, J., Yan, G. J., \& Zhang, X. Y. (2006). Analysis of NDVI and scaled difference vegetation index retrievals of vegetation fraction. Remote Sensing of Environment, 101, 366-378.

Koschke, L., Fürst, C., Frank, S., \& Makeschin, F. (2012). A multi-criteria approach for an integrated land-cover-based assessment of ecosystem services provision to support landscape planning. Ecological Indicators, 21, 54-66.

Lei, L., Cai, X. F., Chen, X., \& Wang, J. (2009). Analysis of natural factors impacting rock desertification in karst areas of Guizhou Province. Journal of Anhui Agricultural Science, 37(9), $4244-4248$ (in Chinese).

Li, L., Tong, L. Q., \& Li, X. H. (2010). Remote-sensing information extraction method based on vegetation coverage. Remote Sensing for Land and Resources, 84(2), 59-62 (in Chinese).
Li, W. H., \& Yu, D. Q. (2002). A study of the technology for remote sensing investigation of rocky desertification in areas of karst stony hills. Remote Sensing of Land and Resources, 1, 34-37 (in Chinese).

Li, Y. B., Shao, J. A., Yang, H., \& Bai, X. Y. (2009). Relations between land use and karst rocky desertification in a typical karst area, China. Environmental Geology, 57, 621-627.

Li, Z., Huffman, T., McConkey, B., \& Townley-Smith, L. (2013). Monitoring and modeling spatial and temporal patterns of grassland dynamics using time-series MODIS NDVI with climate and stocking data. Remote Sensing of Environment, 138, 232-244.

Lillesand, T. M., Kiefer, R. W., \& Chipman, J. W. (2004). Remote sensing and image interpretation (Fifth ed.). New York: John Wiley.

Ling, C., Zhang, H., Lin, H. (2009). Composite vegetation indexes and spatial analysis applied to rock-desertification information extraction. Proceedings, SPIE Second International Conference on Earth Observation for Global Changes, 7471(74710F), pp. 1-9.

Liu, B., Yue, Y. M., Li, Y., Wang, K. L., Zhang, B., \& Tong, Q. X. (2010). Study on the relation between fraction cover and mixed spectral in karst environment. Spectroscopy and Spectral Analysis, 30(90), 2470-2474 (in Chinese).

Liu, Y., \& Lei, H. (2015). Responses of natural vegetation dynamics to climate drivers in China from 1982 to 2011. Remote Sensing, 7, 10243-10268.

Lu, D., \& Weng, Q. (2007). A survey of image classification methods and techniques for improving classification performance. International Journal of Remote Sensing, 28(5), 823-870.

Lü, Y., Zhang, L., Feng, X., Zeng, Y., Fu, B., Yao, X., Yao, X., Li, J., \& Wu, B. (2015). Recent ecological transitions in China: greening, browning, and influential factors. Scientific Reports, 5, 8732 .

Mishra, N. B., \& Chaudhuri, G. (2015). Spatio-temporal analysis of trends in seasonal vegetation productivity across Uttarakhand, Indian Himalayas, 2000-2014. Applied Geography, 56, 29-41.

Montandon, L. M., \& Small, E. E. (2007). The impact of soil reflectance on the quantification of the green vegetation fraction from NDVI. Remote Sensing of Environment, 112, 1835-1845.

Neeti, N., \& Eastman, J. R. (2011). A contextual Mann-Kendall approach for the assessment of trend significance in image time series. Transactions in GIS, 15(5), 599-611.

Neeti, N., Rogan, J., Christman, Z., Eastman, J. R., Millones, M., Schneider, L., Nickl, E., Schmook, B., Turner, B. L., \& Ghimire, B. (2012). Mapping seasonal trends in vegetation using AVHRR-NDVI time series in the Yucatan Peninsula, Mexico. Remote Sensing Letters, 3, 433-442.

Parise, M., De Waele, J., \& Gutiérrez, F. (2009). Current perspectives on the environmental impacts and hazards in karst. Environmental Geology, 58, 235-237.

Parmentier, B. (2014). Characterization of land transitions patterns from multivariate time series using seasonal trend analysis and principal component analysis. Remote Sensing, 2014(6), 12639-12665.

Peng, J., Li, Y., Tian, L., Liu, Y. X., \& Wang, Y. L. (2015). Vegetation dynamics and associated driving forces in Eastern China during 1999-2008. Remote Sensing, 7, 13641-13663. 
Peng, J., Liu, Z. H., Liu, Y. H., Wu, J. S., \& Han, Y. N. (2012b). Trend analysis of vegetation dynamics in Qinghai-Tibet Plateau using Hurst exponent. Ecological Indicators, 14, 28-39.

Peng, J., Liu, Y. Q., Shen, H., Han, Y. N., \& Pan, Y. J. (2012a). Vegetation coverage change and associated driving forces in mountain areas of Northwestern Yunan, China using RS and GIS. Environmental Mornitoring and Assessment, 184, 4787-4798.

Peng, J., Xu, Y. H., Zhang, R., Xiong, K. N., \& Lan, A. J. (2013). Soil erosion monitoring and its implication in a limestone land suffering from rocky desertification in the Huajiang Canyon, Guizhou, Southwest China. Environmental Earth Sciences, 69(3), 831-841.

Pontius Jr., R. G. (2000). Quantification error versus location error in comparison of categorical maps. Photogrammetric Engineering and Remote Sensing, 66(8), 1011-1016.

Price, J. R. (1994). How unique are spectral signatures? Remote Sensing of Environment, 49, 181-186.

Qu, B., Zhu, W., Jia, S., \& Lv, A. (2015). Spatio-temporal changes in vegetation activity and its driving factors during the growing season in China from 1982 to 2011. Remote Sensing, 7, 10243-10268.

Richards, J. A., \& Jia, X. (2006). Remote sensing digital image analysis: an introduction (Fourth ed.). Berlin: SpringerVerlag.

The State Forestry Administration of the People's Republic of China. (2012). Report of Karst Desertification in China. http://www.forestry.gov.cn/portal/zsxh/s/3445/content548741.html.

Tong, L. Q. (2003). A method for extracting remote sensing information from rocky desertification areas in southwest China. Remote Sensing for Land and Resources, 58(4), 3538 (in Chinese).

Tong, L. Q., Liu, C. L., \& Nie, H. F. (2013). Karst rocky desertification investigation and dynamic detection using remote sensing techniques in karst carbonate rocky mountain region, south of China. Beijing: Science Press (in Chinese).

Tong, X., Wang, K., Brandt, M., Yue, Y., Liao, C., \& Fensholt, R. (2016). Assessing future vegetation trends and restoration prospects in the karst regions of southwest China. Remote Sensing, 8, 357.

Wang, S. J., \& Li, Y. B. (2007). Problems and development trends about researches on karst rocky desertification. Advances in Earth Science, 22(6), 573-582 (in Chinese).

Wang, S. J., Li, Y. B., \& Li, R. L. (2003). Karst rocky desertification: formation background, evolution, and comprehensive taming. Journal of Quaternary Science, 23(6), 657-666.

Wang, S. J., Li, R. L., Sun, C. X., Zhang, D. F., Li, F. Q., Zhou, D. Q., Xiong, K. N., \& Zhou, Z. F. (2004b). How types of carbonate rock assemblages constrain the distribution of karst rocky desertified land in Guizhou Province, PR China: phenomena and mechanisms. Land Degradation and Development, 15, 123-131.

Wang, S. J., Liu, Q. M., \& Zhang, D. F. (2004a). Karst rocky desertification in southwestern China: geomorphology, landuse, impact and rehabilitation. Land Degradation and Development, 15, 115-121.

Wardlow, B. D., \& Egbert, S. L. (2008). Large-area crop mapping using time-series MODIS $250 \mathrm{~m}$ NDVI data: an assessment for the U.S. Central Great Plains. Remote Sensing of Environment, 112, 1096-1116.

Weiss, D. J., \& Walsh, S. J. (2009). Remote sensing of mountain environments. Geography Compass, 3(1), 1-21.

Xia, X., Tian, Q., \& Du, F. (2006). Retrieval of rock desertification from multi-spectral remote sensing images. Journal of Remote Sensing, 10(4), 469-474 (in Chinese).

Xiao, R. B., Ouyang, Z. Y., Wang, X. K., \& Zhao, T. Q. (2005). Sensitivity of rocky desertification and its spatial distribution in southwestern China. Chinese Journal of Ecology, 24(5), $551-554$.

Xiong, K. N., Li, P., Zhou, Z. F., An, Y. L., Lv, T., \& Lan, A. J. (2002). The study of karst rocky desertification using GIS and RS tech: a case study of Guizhou Province. Beijing: Geology Press (in Chinese).

Xiong, Y. J., Qiu, G. Y., Mo, D. K., Lin, H., Sun, H., Wang, Q. X., Zhao, S. H., \& Yin, J. (2009). Rocky desertification and its causes in karst areas: a case study in Yongshun County, Hunan Province, China. Environmental Geology, 57, 1481-1488.

Yang, J., Weisberg, P. J., \& Bristow, N. A. (2012). Landsat remote sensing approaches for monitoring long-term tree-cover dynamics in semi-arid woodlands: comparison of vegetation indices and spectral mixture analysis. Remote Sensing of Environment, 119, 62-71.

Yang, Q. Y., Jiang, Z. C., Ma, Z. L., Luo, W. Q., Xie, Y. Q., \& Cao, J. H. (2013). Relationship between karst rocky desertification and its distance to roadways in a typical karst area of Southwest China. Environmental Earth Sciences, 70(1), 295-302.

Yue, Y., Zhang, B., Wang, K., Liu, B., Li, R., Jiao, Q., Yang, Q., \& Zhang, M. (2010). Spectral indices for estimating ecological indicators of karst rocky desertification. International Journal of Remote Sensing, 31(8), 2115-2122.

Yue, Y. M., Wang, K. L., Zhang, B., Liu, B., Chen, H. S., \& Zhang, M. Y. (2011). Uncertainty of remotely sensed extraction of information of karst rocky desertification. Advances in Earth Science, 26(3), 266-274 (in Chinese).

Yuksel, A., Gundogan, R., \& Akay, A. E. (2008). Using the remote sensing and GIS technology for erosion risk mapping of Kartalkaya Dam watershed in Kahramanmaras, Turkey. Sensors, 8, 4851-4865.

Zeng, X. B., Dickinson, R. E., Walker, A., Shaikh, M., Defries, R. S., \& Qi, J. G. (2000). Derivation and evaluation of global 1$\mathrm{km}$ fractional vegetation cover data for land modeling. Journal of Applied Meteorology, 39(6), 826-939.

Zhan, X., Sohlberg, R. A., Townshend, J. R. G., DiMiceli, C., Carroll, M. L., Eastman, J. C., Hansen, M. C., \& DeFries, R. S. (2002). Detection of land cover changes using MODIS $25 \mathrm{~m}$ data. Remote Sensing of Environment, 83, 336-350.

Zhang, Z. M., De Clercq, E. M., Ou, X. K., De Wulf, R. R., \& Verbeke, L. P. C. (2008). Mapping dominant vegetation communities in Meili Snow Mountain, Yunnan Province, China using satellite imagery and plant community data. Geocarto Intenational, 23(2), 135-153.

Zhang, Z. M., Xu, W. H., Zhou, W. Q., Zhang, L., Xiao, Y., Ou, X. K., \& Ouyang, Z. (2014). Integrating remote sensing with GIS-based multi-criteria evaluation approach for karst rocky desertification assessment in Southwest of China. IOP Conference Series: Earth and Environmental Science, 18, 012038. doi:10.1088/1755-1315/18/1/012038. 